\title{
A plasma proteolysis pathway comprising blood coagulation proteases
}

\author{
Lu Yang ${ }^{1, *}$, Yun Li ${ }^{1,2, *}$, Arup Bhattacharya ${ }^{1}$ and Yuesheng Zhang ${ }^{1}$ \\ ${ }^{1}$ Department of Chemoprevention, Roswell Park Cancer Institute, Buffalo, NY, USA \\ 2 Department of Urology, Roswell Park Cancer Institute, Buffalo, NY, USA \\ * These authors have contributed to the work equally \\ Correspondence to: Yuesheng Zhang, email: yuesheng.zhang@roswellpark.org \\ Keywords: amyloid B1-42, coagulation factor VII, coagulation factor XII, prolidase, proteolysis, Pathology Section \\ Received: January 16, $2016 \quad$ Accepted: January 29, 2016 \\ Published: February 07, 2016
}

\section{ABSTRACT}

Coagulation factors are essential for hemostasis. Here, we show that these factors also team up to degrade plasma proteins that are unrelated to hemostasis. Prolidase, SRC and amyloid $\beta 1-42$ (A $\beta 1-42)$ are used as probes. Each probe, upon entering the blood circulation, binds and activates factor XII (FXII), triggering the intrinsic and common coagulation cascades, which in turn activate factor VII, a component of the extrinsic coagulation cascade. Activated factor VII (FVIIa) rapidly degrades the circulating probes. Therefore, FXII and FVIIa serve as the sensor/ initiator and executioner, respectively, for the proteolysis pathway. Moreover, activation of this pathway by one probe leads to the degradation of all three probes. Significant activation of this pathway follows tissue injury and may also occur in other disorders, e.g., Alzheimer's disease, of which Aß1-42 is a key driver. However, enoxaparin, a clinically used anticoagulant, inhibits the proteolysis pathway and elevates plasma levels of the probes. Enoxaparin may also mitigate potential impact of activators of the proteolysis pathway on coagulation. Our results suggest that the proteolysis pathway is important for maintaining low levels of various plasma proteins. Our finding that enoxaparin inhibits this pathway provides a means to control it. Inhibition of this pathway may facilitate the development of disease biomarkers and protein therapeutics, e.g., plasma $A \beta 1-42$ as a biomarker of Alzheimer's disease or recombinant human prolidase as an antitumor agent.

\section{INTRODUCTION}

Proteolysis is essential for cells and organisms and serves many purposes. For example, many proteins undergo limited post-translational proteolytic processing in order to become functionally active, while unwanted or abnormal proteins and peptides are promptly degraded to prevent accumulation or aggregation. Two major intracellular proteolysis pathways are well known: proteolysis in lysosome [1], and ubiquitinationdependent or -independent proteolysis in proteasome [2, 3]. Proteolysis also occurs in the plasma, e.g., limited proteolytic processing of blood coagulation zymogens to become functionally active. However, a plasma proteolysis pathway for eliminating unwanted or abnormal proteins has not been previously shown. Various endogenous or exogenous proteins and peptides may enter the blood circulation, some of which may not have any physiological functions in the blood or may even be harmful. The fate of these substances in the plasma is not well understood, although certain plasma proteins may be removed through renal elimination, hepatic elimination or the immune system along with endocytosis and degradation by the intracellular proteolysis pathways $[4,5]$.

In this paper, we show that blood coagulation factors work in concert to enable proteolysis of non-coagulation factors in the plasma, including prolidase, also known as peptidase D (PEPD), SRC and amyloid $\beta 1-42$ (A $\beta 1-42$ ), and discuss clinical implications of this finding. PEPD is mainly an intracellular protein, a dipeptidase involved in collagen metabolism [6]. Interestingly, we recently found that recombinant human PEPD inhibits tumor growth by targeting epidermal growth factor receptor (EGFR), also known as ERBB1, and its family member ERBB2 [7, 
8]. SRC is an intracellular non-receptor protein tyrosine kinase [9]. Both PEPD and SRC are present in the plasma at low levels under normal circumstances, as shown in the present study, presumably due to their release from damaged cells and tissues. A $\beta 1-42$ is a peptide generated from proteolytic cleavage of cell-membrane-bound $A \beta$ precursor protein by secretases and is critically involved in the development of Alzheimer's disease (AD) [10]. A $\beta 1$ 42 is also present in the plasma at low levels under normal circumstances. PEPD, SRC and A $\beta 1-42$ were evaluated as three probes to show how different substrates may engage the plasma proteolysis pathway and also in view of the potential clinical implications of their degradation in the plasma.

\section{RESULTS}

\section{PEPD is degraded in the plasma by coagulation proteases but enoxaparin inhibits the degradation}

Average plasma level of mouse PEPD (mPEPD) was $0.9 \mathrm{nM}$ in control mice, which is very similar to our previously obtained values [11], and average plasma levels of total PEPD (hPEPD plus mPEPD) increased 19.4- and 15.1-fold at 1 and $24 \mathrm{~h}$, respectively, following intraperitoneal injection (i.p.) of recombinant human PEPD (hPEPD) at $10 \mathrm{mg} / \mathrm{kg}$ (Figure 1A). Surprisingly,
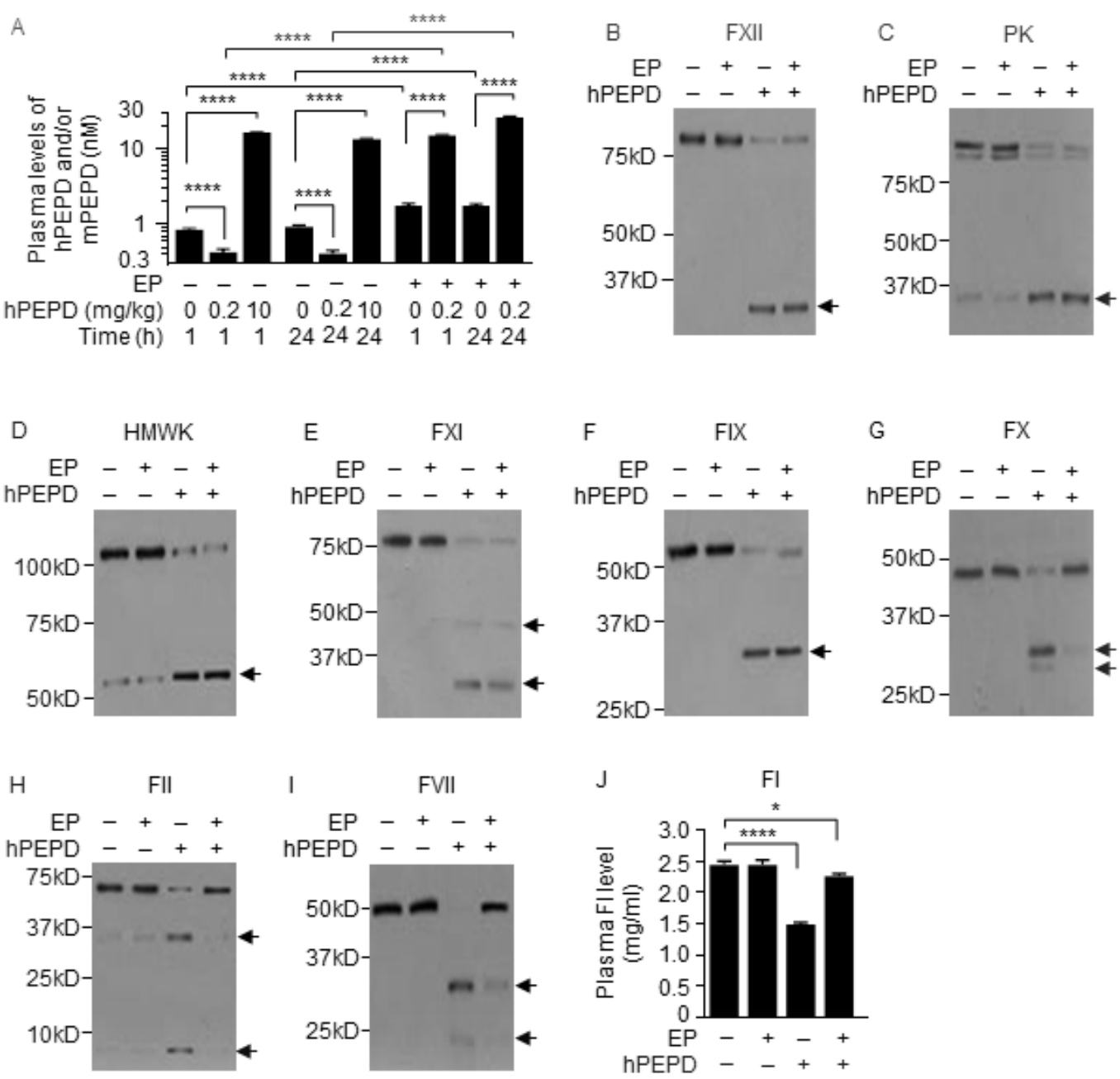

Figure 1: PEPD degradation in the plasma. A. Plasma PEPD concentrations in WT mice treated with EP and/or hPEPD. EP (2.5 $\mathrm{mg} / \mathrm{kg})$ was given to mice i.p. once daily for 5 days. hPEPD $(0.2$ or $10 \mathrm{mg} / \mathrm{kg})$ or vehicle was given to mice i.p. alone or $1 \mathrm{~h}$ after the last EP dose. Blood samples were collected from the mice at 1 or $24 \mathrm{~h}$ after $\mathrm{hPEPD} /$ vehicle treatment for measurement of plasma PEPD by enzyme-linked immunosorbent assay (ELISA). B.-J. Changes in plasma coagulation factors in WT mice treated with EP and/or hPEPD. Mice were treated with EP as described in A. hPEPD $(0.2 \mathrm{mg} / \mathrm{kg})$ or vehicle was given to mice i.p. alone or $1 \mathrm{~h}$ after the last EP dose; blood samples were collected from the mice at $6 \mathrm{~h}$ after $\mathrm{hPEPD} /$ vehicle treatment; $7.5 \mu \mathrm{l}$ plasma per sample was analyzed by immunoblotting (IB). Arrows indicate cleaved fragments. Plasma level of FI was measured by ELISA. Error bars in A and J indicate SD ( $n=3$ ). Data were analyzed by two-way ANOVA in A or one-way ANOVA in J, followed by Tukey multiple comparisons test. Data in A were log transformed before ANOVA. * $p<0.05 ; * * * * p<0.0001$. 
at 1 and $24 \mathrm{~h}$ following hPEPD injection at $0.2 \mathrm{mg} / \mathrm{kg}$, average plasma levels of total PEPD were only $51 \%$ and $46 \%$ of control, respectively (Figure 1A). This suggested that hPEPD might elicit rapid elimination of itself and mPEPD from plasma in mice.

Activators of antithrombin seem to elevate plasma PEPD level in rats [12]. We treated mice with enoxaparin (EP), a clinically used low molecular weight heparin which activates antithrombin III, at $2.5 \mathrm{mg} / \mathrm{kg}$ i.p. daily for 5 days and gave hPEPD $(0.2 \mathrm{mg} / \mathrm{kg})$ i.p. at $1 \mathrm{~h}$ after the last EP dose; average plasma levels of total PEPD were 35.2- and 63.8-fold higher at 1 and $24 \mathrm{~h}$, respectively, following hPEPD treatment than in mice treated with the same dose of hPEPD alone (Figure 1A). EP also increased average plasma level of mPEPD by 2.1-fold (Figure 1A). hPEPD treatment caused cleavage or activation of many coagulation factors in mice, including factor XII (FXII), prekallikrein (PK), high molecular weight kininogen (HMWK), factor XI (FXI), factor IX (FIX), factor X (FX), factor II (FII), factor I (FI) and factor VII (FVII) (Figure 1B-1J). FXII, PK, HMWK, FXI, FIX are components of the intrinsic blood coagulation cascade [13], whereas FVII belongs to the extrinsic blood coagulation cascade, which is typically activated via tissue factor (TF) upon blood vessel damage. The two cascades converge on FX, activation of which leads to FII activation, which cleaves FI [14]. EP itself had no effect on these factors and failed to prevent hPEPD from activating FXII, PK, HMWK, FXI and FIX, but prevented hPEPD from causing activation or cleavage of FX, FII, FI and FVII (Figure 1B-1J). EP is known to inhibit FIXa, FXa and FIIa (the active forms of FIX, FX and FII) by activating antithrombin III [15, 16]. Because both FIIa and FXa can activate FVII [17], it suggested that hPEPD activated FVII by activating the intrinsic and common coagulation cascades. Although hPEPD is of human origin and has a His tag, injecting $\mathrm{mPEPD}$ without any tag to mice elicited the same response as did hPEPD (Supplementary Figure 1C-1L).

We next evaluated the effects of several human coagulation factors on hPEPD. We focused on FXa, FIIa and FVIIa (active form of FVII), as EP inhibition of PEPD degradation was associated with inhibition of these factors. FXa and FIIa had no effect on hPEPD stability (Supplementary Figure 2A-2D), but FVIIa $(10 \mathrm{nM})$ plus TF $(10 \mathrm{nM})$ caused rapid and extensive hPEPD proteolysis (Figure 2A-2C). For example, only $35.9 \%, 46.3 \%$ and $52.4 \%$ of hPEPD remained after it was incubated at 10, 40 and $90 \mathrm{nM}$ with FVIIa and TF for $60 \mathrm{~min}$, respectively (Figure 2B). Notably, given that the normal plasma concentration of FVII is approximately $10 \mathrm{nM}$ [18], the FVIIa concentration used in the above experiment is probably much higher than its physiological concentration, which was intended to facilitate detection of its activity. However, as described later, FVIIa is essential for hPEPD degradation in the plasma. Although TF enhances the proteolytic activity of FVIIa, as expected, it may not necessarily be involved in PEPD degradation by FVIIa in vivo, as TF is present in subendothelial tissue, and no blood vessel injury appears to be involved in the activation of FVII and other coagulation proteases in mice injected with hPEPD. While a soluble bioactive form of TF circulates in blood [19], potential involvement of this factor in PEPD degradation by FVIIa remains unknown. Notably, FVIIa in the absence of TF degraded hPEPD (Figure 2D). Moreover, while FVII with or without TF showed no proteolytic activity towards hPEPD, adding FIIa at a physiologically relevant concentration $(100 \mathrm{nM})$ [20] to the mixture caused marked hPEPD degradation (Figure 2E). These results further show that hPEPD activates FVII via the intrinsic and common coagulation cascades and also reveal that FVIIa degrades hPEPD. FVIIa is a trypsin-like serine protease, cleaving peptide bonds at the carboxyl side of arginine and lysine [21] and is known to cut FIX and FX. The extensive proteolysis of hPEPD by FVIIa, however, contrasts with its limited proteolysis of FIX (two proteolytic sites) and FX (one proteolytic site) $[22,23]$. The proteolytic sites in hPEPD for FVIIa are not yet known.

\section{hPEPD directly binds and activates FXII}

We next evaluated the interaction of hPEPD with several human coagulation factors. FXII interacts with HMWK, PK and FXI to initiate the intrinsic coagulation cascade [24], but hPEPD binds only to FXII (Figure $3 \mathrm{~A})$. hPEPD is a homodimeric protein, with each subunit composed of 493 amino acids, containing the $\mathrm{N}$-terminal regulatory domain, a linker and the $\mathrm{C}$-terminal catalytic domain (amino acids \#1-174, 175-185 and 186-493, respectively) $[25,26]$. We evaluated the interaction of FXII with four hPEPD mutants, including $278 \mathrm{G}>\mathrm{D}$ hPEPD, 1M-265Rdel-hPEPD, 185V-493Kdel-hPEPD and 266T-493Kdel-hPEPD (Supplementary Figure 3). The mutants, except 278G $>$ D-hPEPD, cannot form homodimers [7]. Enzymatically inactive 278G $>$ DhPEPD [27] and 1M-265Rdel-hPEPD were almost indistinguishable from hPEPD in FXII binding, while neither185V-493Kdel-hPEPD nor 266T-493Kdel-hPEPD could bind to FXII (Figure 3B). FXII is a single chain zymogen; proteolytic cleavage at R353-V354 generates FXIIa, with the N-terminal heavy chain and C-terminal catalytic light chain ( $\beta$-FXIIa) held together by a disulfide bond [28]. hPEPD and 278G $>$ D-hPEPD did not differ in activating FXII, whereas 1M-265Rdel-hPEPD was about 50\% active (Figure 3C). These results show: 1) the enzymatic function of hPEPD is not involved in FXII binding and activation; 2) each hPEPD monomer binds to FXII independently; 3) the C-terminal sequence of hPEPD binds to FXII, but additional sequence in hPEPD is involved in full XII activation. $\mathrm{Zn}^{2+}$ is involved in FXII activation [29]. FXII activation by hPEPD also required $\mathrm{Zn}^{2+}$ (Figure 3D). 
A

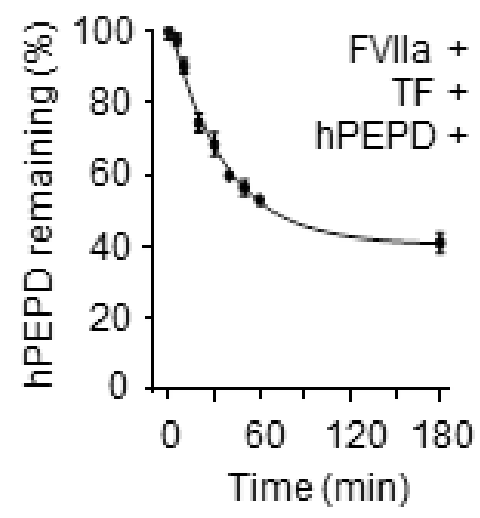

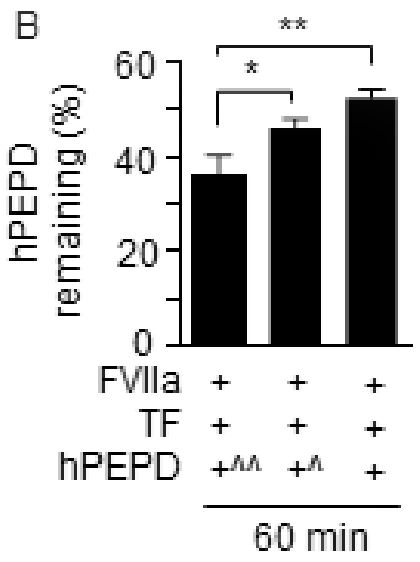

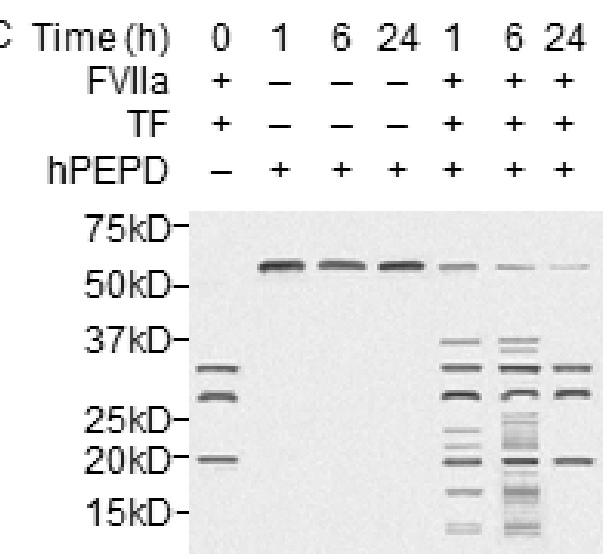

D

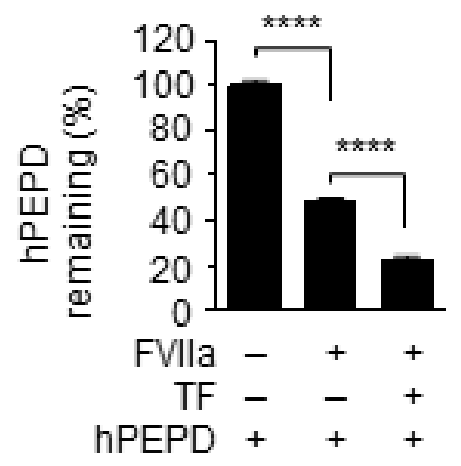

E

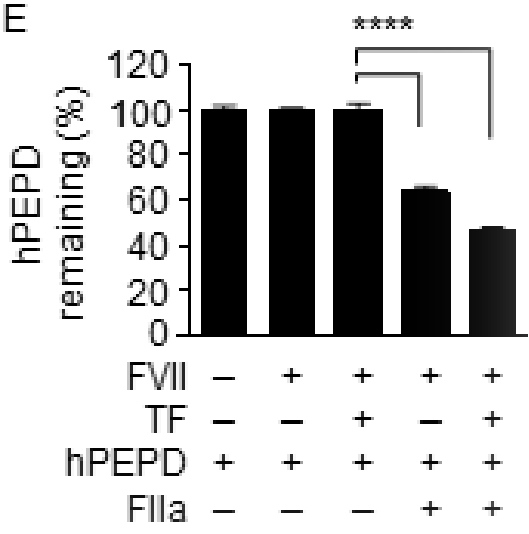

Figure 2: hPEPD degradation by FVIIa. A. hPEPD $(90 \mathrm{nM})$ was incubated with FVIIa $(10 \mathrm{nM})$ plus TF $(10 \mathrm{nM})$ in $\mathrm{CaCl}_{2}$-containing phosphate-buffered saline (PBS) at room temperature (RT), and then measured at different times for remaining hPEPD by enzymatic activity analysis. B. $\mathrm{hPEPD}$ at $10 \mathrm{nM}\left({ }^{\wedge \wedge}\right), 40 \mathrm{nM}\left({ }^{+\wedge}\right)$ or $90 \mathrm{nM}(+)$ was incubated with FVIIa $(10 \mathrm{nM})$ plus TF $(10 \mathrm{nM})$ in $\mathrm{CaCl}_{2}^{-}$ containing PBS at RT for $60 \mathrm{~min}$; remaining hPEPD was measured by enzymatic activity analysis. C. hPEPD $(90 \mathrm{nM})$ was incubated alone or with FVIIa $(10 \mathrm{nM})$ plus TF $(10 \mathrm{nM})$ in $\mathrm{CaCl}_{2}$-containing PBS at $\mathrm{RT}$, and then separated by sodium dodecyl sulfate polyacrylamide gel electrophoresis (SDS-PAGE) and stained by silver. FVIIa and TF were also incubated without hPEPD, as a control. D. hPEPD (90 nM) was incubated with FVIIa $(10 \mathrm{nM})$ with or without TF $(10 \mathrm{nM})$ in $\mathrm{CaCl}_{2}$-containing PBS at RT, followed by measurement of remaining hPEPD enzymatic activity. E. hPEPD $(90 \mathrm{nM})$ was incubated alone, with FVII $(10 \mathrm{nM})$, with FVII $(10 \mathrm{nM})$ plus TF $(10 \mathrm{nM})$, with FVII (10 nM) plus FIIa $(100 \mathrm{nM})$, or with FVII $(10 \mathrm{nM})$ plus TF $(10 \mathrm{nM})$ and FIIa $(100 \mathrm{nM})$ in $\mathrm{CaCl}_{2}$-containing PBS at RT for $24 \mathrm{~h}$, followed by measurement of remaining hPEPD by enzymatic analysis. Error bars in A, B, D and E indicate $\mathrm{SD}(n=3)$. Data in B, D and E were analyzed by one-way ANOVA, followed by Tukey multiple comparisons test. * $p<0.05 ; * * p<0.01 ; * * * p<0.0001$. 
We next compared human FXII with its mutants for binding to hPEPD, including 20I-50Pdel-FXII, 153T-172Rdel-FXII, 315L-368Sdel-FXII, 6PsdelFXII, and 13Ps $>13$ As-FXII (Supplementary Figure 4A-4D). While negatively charged surfaces and other substances activate FXII by binding to sequences within the fibronectin type II domain (FN2D) or fibronectin type I domain (FN1D) in FXII [28], FXII mutants lacking the relevant binding sites (20I-50Pdel-FXII and 153T-172Rdel-FXII) bound to hPEPD as well as did FXII (Figure 3E). However, the FXII mutant lacking the proline-rich domain (PRD; 315L-368Sdel-FXII) could not bind to hPEPD (Figure 3E). Of the 13 prolines in the PRD of FXII (Supplementary Figure 4A), deletion of the first 6 prolines (6Psdel-FXII) only slightly attenuated FXII binding to hPEPD, whereas replacing all 13 prolines with 13 alanines $13 \mathrm{Ps}>13 \mathrm{As}-\mathrm{FXII}$ completely abolished its binding to hPEPD (Figure 3E). These results show that hPEPD binds to FXII via PRD and that most if not all of the prolines are involved in the binding. This also reveals a physiological function of PRD in FXII.

\section{FXII initiates PEPD degradation in the plasma}

We further studied plasma PEPD degradation using FXII knockout mice (C57BL/6-FXII ${ }^{-/}$), their WT counterparts, and EP. As expected, FXII was absent in the plasma of $\mathrm{FXII}^{-/-}$mice (Supplementary Figure 5), in which exons 3-8 of the FXII gene is replaced with the neomycin resistance gene [30]. Basal plasma level of mPEPD was 2.2-fold higher in $\mathrm{FXII}^{-/}$mice than in WT mice (Figure 4A). EP treatment ( $2.5 \mathrm{mg} / \mathrm{kg}$ i.p. daily for 5 days) elevated plasma level of mPEPD by 2.0 -fold in WT mice but not in $\mathrm{FXII}^{-/-}$mice (Figure 4A). Without EP pretreatment, at $6 \mathrm{~h}$ following hPEPD treatment $(0.2 \mathrm{mg} / \mathrm{kg}$ i.p. $)$, plasma level of total PEPD decreased 66\% in WT mice, as shown before, but increased 12.5-fold in $\mathrm{FXII}^{-/-}$mice (Figure 4A); average plasma level of total PEPD is 53.8-fold higher in $\mathrm{FXII}^{-/-}$mice than in WT mice. With EP pretreatment, at $6 \mathrm{~h}$ following hPEPD treatment $(0.2 \mathrm{mg} / \mathrm{kg}$ i.p. $)$, average plasma level of total PEPD was $19.7 \mathrm{nM}$ in WT mice, which is still $14.6 \%$ lower than in $\mathrm{FXII}^{-/}$mice (Figure 4A), indicating that EP did not fully inhibit FXII-initiated PEPD degradation in WT mice. However, EP did not show a significant effect on plasma PEPD level in $\mathrm{FXII}^{-/}$mice (Figure 4A). These results show that FXII is essential
A

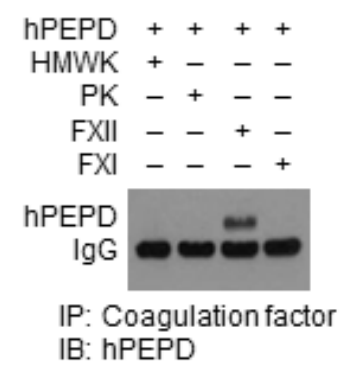

$\mathrm{B} \quad \mathrm{hPEPD}+-\ldots+\ldots$

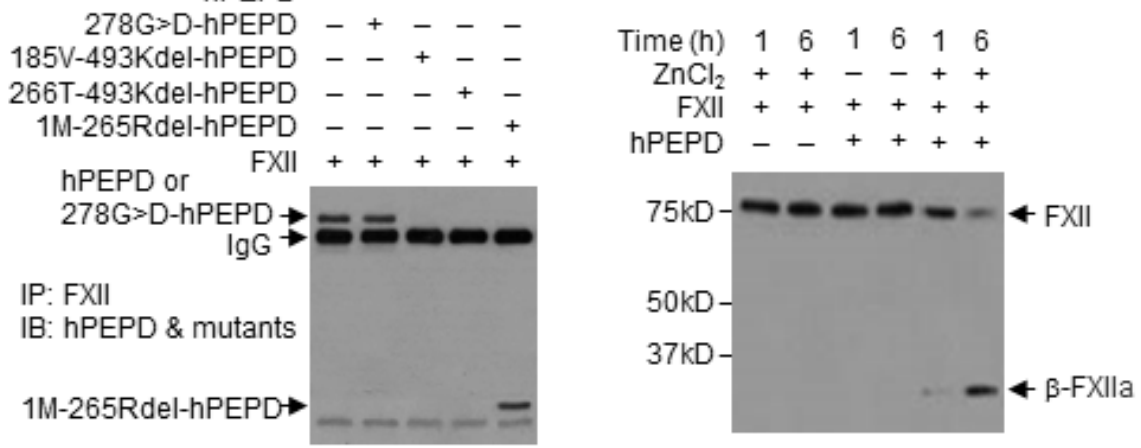

C

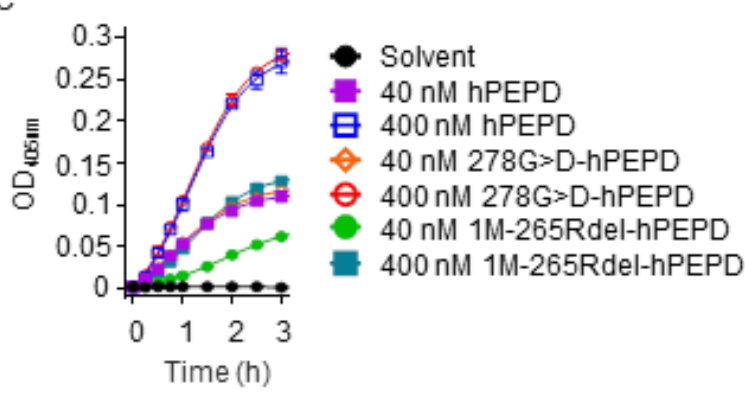

E hPEPD +++++++

FXII +---+--
$201-50$ Pdel-FXII -+----

153T-172Rdel-FXII - $+\ldots+-$

315L-368Sdel-FXII $-\ldots++-$

6Psdel-FXII -

13Ps $>13$ As-FXII $-\ldots+-$

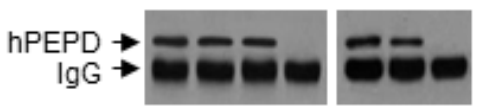

IP: FXII \& mutants

IB: hPEPD

Figure 3: hPEPD binds to PRD in FXII and activates FXII. A., B. hPEPD or a mutant (40 nM) was incubated with a blood coagulation factor $(0.5 \mu \mathrm{M})$ in PBS at $37^{\circ} \mathrm{C}$ for $2 \mathrm{~h}$, followed by immunoprecipitation (IP) and IB. C. FXII (0.97 nM) was incubated with hPEPD or a mutant in $\mathrm{ZnCl}_{2}$-containing PBS at RT; FXII activation was measured by a chromogenic assay. Error bars indicate SD $(n=3)$. D. hPEPD $(40 \mathrm{nM})$ was incubated with FXII $(0.5 \mu \mathrm{M})$ in PBS $(0.1 \mathrm{ml}$ volume $)$ with or without $\mathrm{ZnCl}_{2}(15 \mu \mathrm{M})$ at RT, followed by IB $(7.5$ $\mu 1$ per sample). E. FXII or a mutant $(0.5 \mu \mathrm{M})$ was incubated with hPEPD $(40 \mathrm{nM})$ in PBS at $37^{\circ} \mathrm{C}$ for $2 \mathrm{~h}$, followed by IP and IB. 
for degradation of plasma PEPD. In $\mathrm{FXII}^{-/-}$mice, hPEPD treatment caused no activation of HMWK, FXI, PK and FIX, but slight activation of FX, FII and FVII (FI was not measured), which was largely inhibited by EP (Figure 4B). The mechanism of FXII-independent activation of FX, FII and FVII by hPEPD remains unknown, but hPEPD does not directly activate any of these factors (Supplementary Figure 6). Our results do not show that FXII-independent activation of FVII contributes significantly to plasma PEPD degradation. Lack of EP effect on plasma PEPD level in $\mathrm{FXII}^{-/-}$mice, contrary to its ability to markedly elevate plasma PEPD level in WT mice (Figure 1A), also further shows that EP elevates plasma PEPD level in WT mice by inhibiting the FXII-mediated proteolysis pathway, rather than by modulating PEPD exit from plasma, e.g., its sequestration in the matrix or its uptake by cells. Collectively, we conclude that plasma PEPD degradation originates from direct FXII activation by PEPD.

\section{Plasma PEPD is degraded exclusively by FVIIa}

We next turned to FVII-deficient mice. Replacement of both FVII alleles in mice with a construct containing the tetracycline transactivator (tTA) promoter attached to the FVII cDNA (FVII ${ }^{\mathrm{tTA} / \mathrm{TA}}$ ) results in negligible FVII expression [31]. FVII was undetectable in the plasma of FVII ${ }^{\mathrm{tTA} / \mathrm{TA}}$ mice (Supplementary Figure 5). We compared the hPEPD-degrading activities of plasma samples from FVII $^{\text {tTA/tTA }}$ mice and WT mice. Notably, blood was drawn from mice without an anticoagulant (EDTA), in order to assess the activities of FVII and other factors, but was immediately centrifuged to remove cells and platelets. Under the same experimental condition, no degradation of hPEPD could be detected after incubation with FVII ${ }^{\mathrm{tTA} /}$ tTA plasma, but only $88.8 \%$ of hPEPD remained after incubation with WT plasma (Figure 5A), implying the presence of a low level of FVIIa in WT plasma, either preformed or generated during the incubation. Adding human FIIa or FXa to WT plasma markedly enhanced hPEPD degradation, but neither factor was effective in FVII $^{\text {tAA/tTA }}$ plasma (Figure 5A). Notably, all incubated solutions were cleared of precipitates (potential fibrin clots) by centrifugation before analysis. The precipitates after wash with PBS were suspended in $2.5 \%$ SDS and analyzed by IB for presence of hPEPD, using factor XIIIa (FXIIIa) as the binding control, since FXIIIa is known to bind to fibrin [32]. However, no hPEPD could
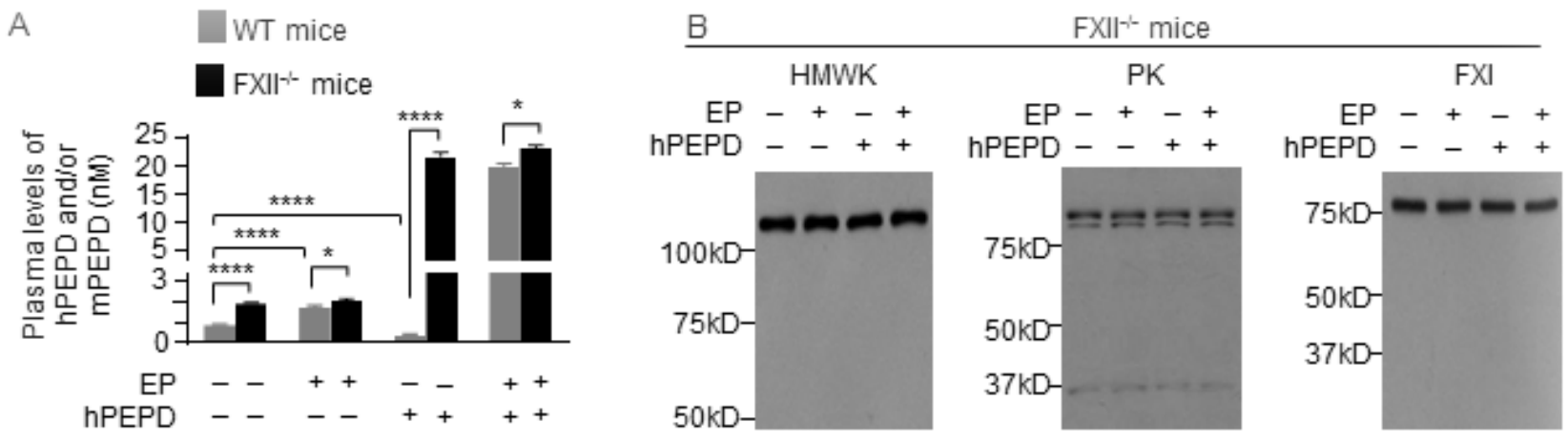

B

FXII $\vdash$ mice

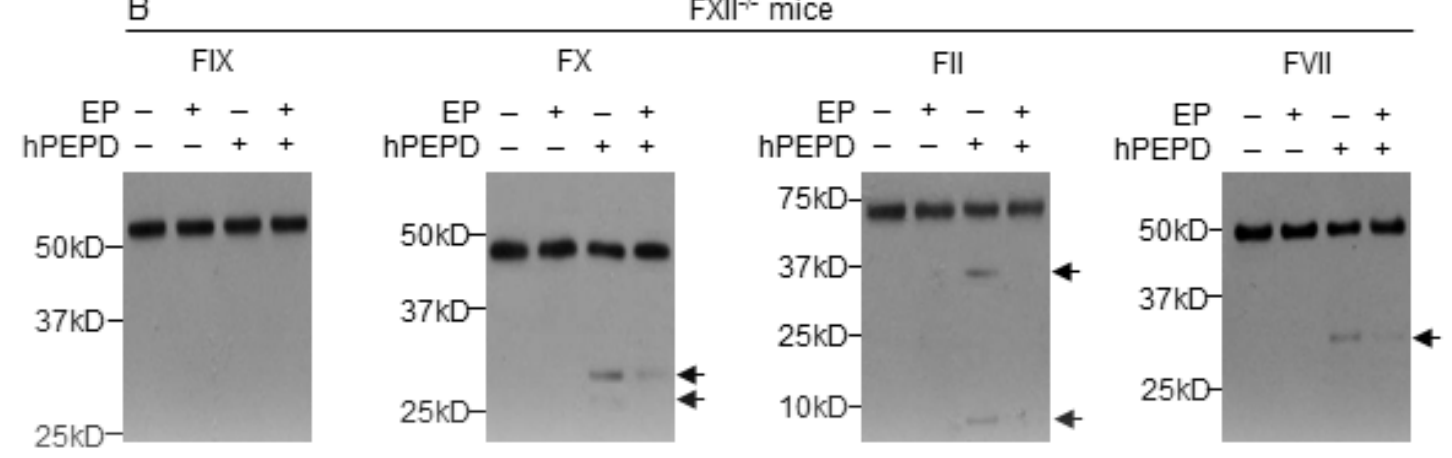

Figure 4: FXII initiates plasma PEPD degradation. A. Plasma PEPD concentrations in control mice and mice treated with EP, hPEPD, or EP plus hPEPD. EP $(2.5 \mathrm{mg} / \mathrm{kg})$ was given to mice i.p. once daily for 5 days; hPEPD $(0.2 \mathrm{mg} / \mathrm{kg})$ or vehicle was given to mice i.p. alone or at $1 \mathrm{~h}$ after the last EP dose. Blood samples were collected from the mice at $6 \mathrm{~h}$ after $\mathrm{hPEPD} /$ vehicle treatment for measurement of plasma PEPD level by ELISA. Error bars indicate SD $(n=3)$. Data were log transformed before two-way ANOVA, followed by Tukey multiple comparisons test. ${ }^{*} p<0.05$; *** $p<0.0001$. B. Changes in plasma coagulation factors in mice treated as described in A; $7.5 \mu 1$ plasma per sample was analyzed by IB. Arrows indicate cleaved fragments. 
be detected in any of the samples (Figure 5B), although FXIIIa was also absent in two samples, apparently due to loss of the minute amount of precipitates during PBS wash. Moreover, removal of FVII/FVIIa from WT plasma by immunodepletion abolished the residual hPEPD degradation or FIIa-enabled hPEPD degradation (Figure 5C and 5D). Basal plasma level of mPEPD was 2.5-fold higher in $\mathrm{FVII}^{\mathrm{tTA} / \mathrm{TTA}}$ mice than in WT mice (Figure 5E). At $6 \mathrm{~h}$ following hPEPD treatment $(0.2 \mathrm{mg} / \mathrm{kg}$ i.p. $)$, plasma level of total PEPD decreased $56.3 \%$ in WT mice but increased 12.0-fold in FVII ${ }^{\mathrm{tTA} / \mathrm{TA}}$ mice, differing by 68.9fold between the two genotypes (Figure 5E). FVII ${ }^{\mathrm{tTA} / \mathrm{TA} A}$ mice closely resemble $\mathrm{FXII}^{-/}$mice with regard to their inability to degrade plasma PEPD, but the coagulation factors that were not activated in hPEPD-treated $\mathrm{FXII}^{-/}$ mice, as shown in Figure 4B, were all activated in hPEPDtreated FVII ${ }^{\mathrm{TA} / \mathrm{TTA}}$ mice, excluding FVII (Figure 5F). Collectively, we conclude that plasma PEPD is degraded exclusively by FVIIa and that both FXa and FIIa, formed after FXII activation by PEPD, activate FVII.

\section{Degradation of plasma SRC by the FXII-FVII proteolysis pathway}

Many proteins bind to proline-rich motifs via SH3, WW or EVH1 domains [33-35]. We examined the interaction of SH3-containing mouse SRC (mSRC) with the FXII-FVII pathway. Although mSRC is an intracellular tyrosine kinase, it is present in plasma at a low concentration as shown later, probably due to release from damaged cells. mSRC directly bound and activated FXII (Figure 6A and 6B). Deletion of the PRD in FXII (315L-368Sdel-FXII) completely abolished mSRC binding, but binding was not altered by deletion of the sequences in FN2D or FN1D that binds to negatively charged surfaces and other substances (20I-50Pdel-FXII or 153T-172Rdel-FXII) (Figure 6A). However, mSRC differs from hPEPD in that its binding to FXII was severely reduced after deletion of the first 6 prolines in the PRD of FXII (Figure 6A), whereas such deletion only slightly
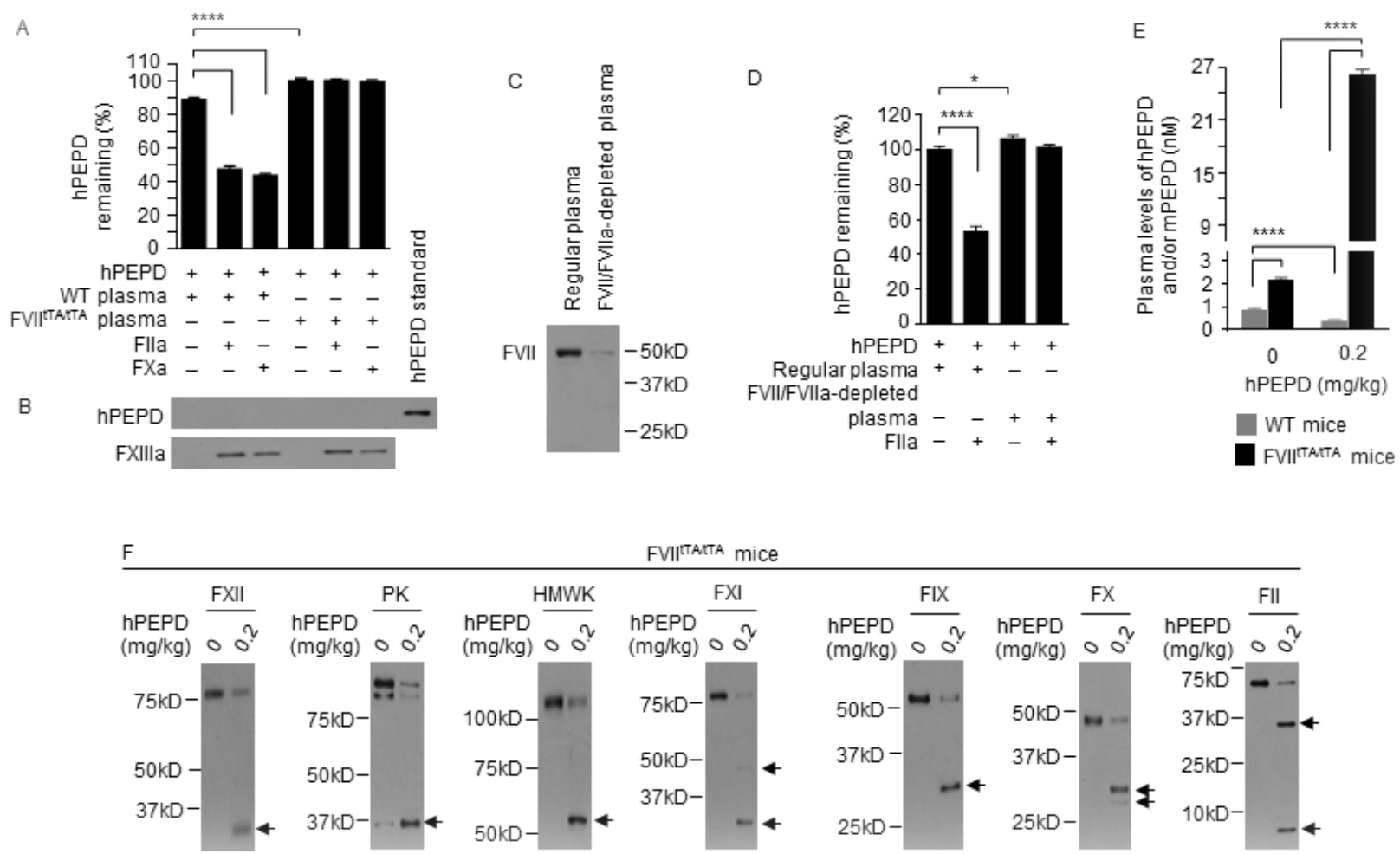

Figure 5: Plasma PEPD is degraded exclusively by FVIIa. A., B. hPEPD ( 9.2 pmol) was incubated at RT with plasma (100 $\mu$ l) with or without FIIa or FXa $(10 \mathrm{pmol})$ for $24 \mathrm{~h}$ and after centrifugation to remove the precipitates, remaining PEPD was measured by enzymatic activity analysis. The precipitates were washed by PBS and checked for presence of hPEPD by IB, using FXIIIa and pure hPEPD as a binding control and standard, respectively. C. Plasma samples from untreated WT mice were incubated with an antibody that binds to both FVII and FVIIa; the immunocomplexes were pulled down with protein A sepharose. The supernatant fraction along with a regular plasma sample was analyzed for FVII/FVIIa level by IB. FVIIa was undetectable in the samples. D. hPEPD (9.2 pmol) was incubated with regular plasma or FVII/FVIIa-depleted plasma $(100 \mu \mathrm{l})$ in the absence or presence of FIIa (10 pmol) at RT for $24 \mathrm{~h}$; remaining hPEPD was measured by hPEPD enzymatic activity. Notably, plasma samples used in A-D were prepared from blood drawn from mice without an anticoagulant. E., F. Plasma PEPD and coagulation factors in control mice and mice at $6 \mathrm{~h}$ after hPEPD treatment; PEPD concentration was measured by ELISA, and coagulation factors were analyzed by IB (7.5 $\mu 1$ plasma per sample). Arrows indicate cleaved fragments. Error bars in A, D and E indicate SD $(n=3)$. Data were analyzed by one-way ANOVA in A or two-way ANOVA in D and E, followed by Tukey multiple comparisons test. Data in E were log transformed before ANOVA. ${ }^{*} p<0.05 ; * * * *<0.0001$. 
attenuated hPEPD binding to FXII as described before. Incubation of mSRC with FVIIa $(10 \mathrm{nM})$ and $\mathrm{TF}$ resulted in time-dependent and extensive mSRC fragmentation (Figure 6C); thus, mSRC is also a substrate of FVIIa. The exact proteolytic sites in mSRC for FVIIa are not yet known. Average plasma level of endogenous $\mathrm{mSRC}$ was $3.4 \mathrm{nM}$ in WT mice, but was 2.1- and 2.2fold higher in $\mathrm{FXII}^{-/}$mice and $\mathrm{FVII}^{\mathrm{ITA} / \mathrm{TA} A}$ mice respectively (Figure 7A). In WT mice, average plasma level of total mSRC was $49 \%$ and $147 \%$ of control at 6 h post i.p. injection of $\mathrm{mSRC}$ at 0.1 or $0.5 \mathrm{mg} / \mathrm{kg}$, respectively (Figure 7A). The effect of the low dose of mSRC on plasma level of total SRC is reminiscent of that seen with low dose of hPEPD as shown in Figure 1A. At $6 \mathrm{~h}$ post $\mathrm{mSRC}$ injection described above, average plasma level of total $\mathrm{mSRC}$ was 45.2-58.2-fold higher in $\mathrm{FXII}^{-/-}$mice and 62.2-fold higher in FVII ${ }^{\mathrm{ITA} / \mathrm{TA}}$ mice (treated with $\mathrm{mSRC}$ only at $0.5 \mathrm{mg} / \mathrm{kg}$ ) than in WT mice (Figure 7A). Analysis of plasma samples showed that mSRC injection caused dose-related activation/cleavage of FXII, PK, HMWK, FXI, FIX, FX, FII, FI and FVII in WT mice, no change in any of the factors in $\mathrm{FXII}^{-/-}$mice, and activation of all the factors, excluding FVII, in FVII ${ }^{\mathrm{tTA} / \mathrm{TA}}$ mice (Figure 7B$7 \mathrm{~J})$. Unlike hPEPD and mPEPD, however, mSRC caused no FXII-independent activation of FX, FII and FVII. We did not measure FI cleavage in $\mathrm{FXII}^{-/}$mice and $\mathrm{FVII}^{\mathrm{tTA} /}$ ${ }^{\text {tTA }}$ mice. Collectively, our results show that the FXII-FVII pathway also detects and degrades mSRC.
A

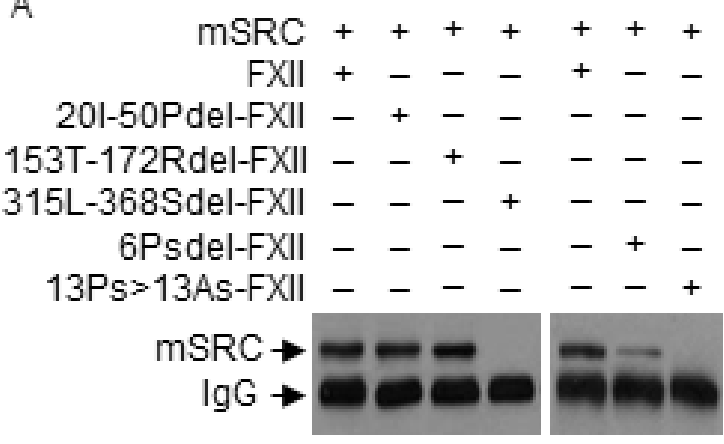

IP: FXII or its mutants; IB: mSRC

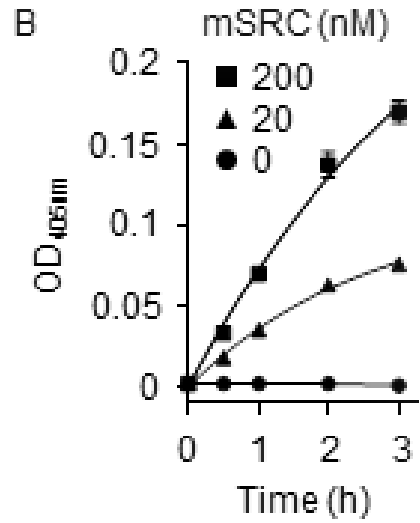

Time (h)

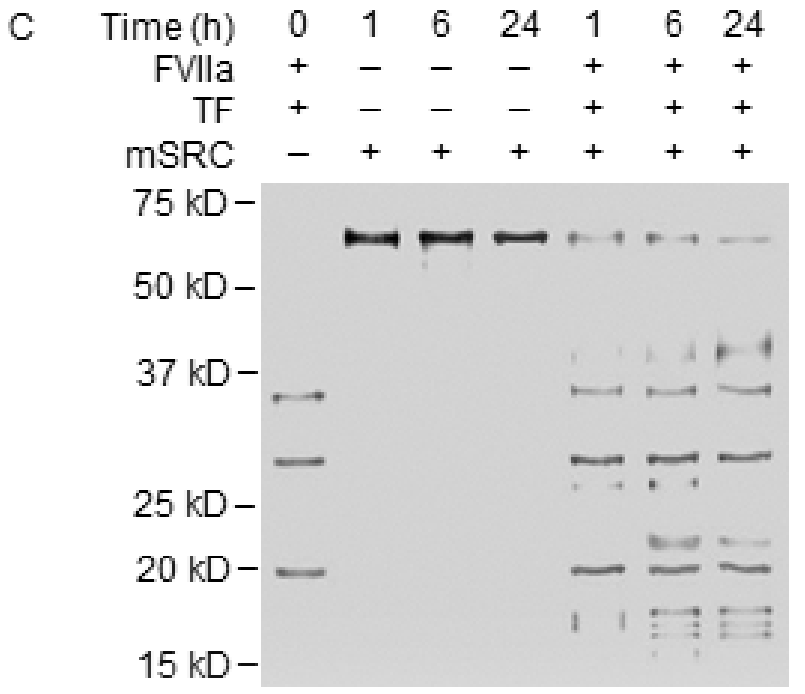

Figure 6: SRC binds to PRD in FXII and activates FXII but is degraded by FVIIa. A. mSRC (40 nM) was incubated with FXII or a mutant $(0.5 \mu \mathrm{M})$ in PBS at $37^{\circ} \mathrm{C}$ for $2 \mathrm{~h}$, followed by IP and IB. B. mSRC $(0,20$ and $200 \mathrm{nM})$ was incubated with FXII $(0.97$ $\mathrm{nM})$ in $\mathrm{ZnCl}_{2}$-containing PBS at RT; FXII activation was measured by a chromogenic assay. Each value is mean $\pm \mathrm{SD}(n=3)$. C. $\mathrm{mSRC}$ $(0.17 \mu \mathrm{M})$ was incubated alone or with FVIIa $(10 \mathrm{nM})$ and TF $(10 \mathrm{nM})$ in $\mathrm{CaCl}_{2}$-containing PBS at RT for indicated times, separated by SDS-PAGE and stained by silver. FVIIa and TF were incubated without $\mathrm{mSRC}$ as a control. 


\section{Degradation of plasma A $\beta 1-42$ by the FXII-FVII proteolysis pathway}

human $\mathrm{A} \beta 1-42$ (hA $\beta 1-42)$ also activates human FXII in a dose-dependent manner (Figure 8A), but comparison of hA $\beta 1-42$ binding by FXII and its mutants showed that hA $\beta 1-42$ binds to FN2D (20I-50P) in FXII (Figure $8 B$ ). Incubation of hA $\beta 1-42$ with FVIIa $(10 \mathrm{nM})$ and TF resulted in time-dependent and extensive hAß1-42 fragmentation (Figure $8 \mathrm{C}$ ). The cleavage pattern indicates that hA $\beta 1-42$ is likely cleaved by FVIIa at all three sites where an arginine (residue \#5) or a lysine (residues \#16, 28 ) exists. The high molecular weight bands that formed after FVIIa treatment (Figure 8C) may be aggregates of hA $\beta 1-42$ or its fragments, as $h A \beta 1-42$ is prone to aggregation.

Average plasma level of endogenous mouse $\mathrm{A} \beta 1-42$ (mAß1-42) was $0.1 \mathrm{nM}$ in WT mice, but was 2.2-2.6-fold higher in $\mathrm{FXII}^{-/}$mice and $\mathrm{FVII}^{\mathrm{TTA} / \mathrm{TA}}$ mice (Figure 9A). In WT mice, at $6 \mathrm{~h}$ after i.p. injection of hA $\beta 1-42$ at $2 \mu \mathrm{g} /$ $\mathrm{kg}$, plasma level of total A $\beta 1-42$ (mA $\beta 1-42$ plus hA $\beta 1$ 42) decreased $39.3 \%$, but it increased 1.5- and 5.1-fold after hA $\beta 1-42$ injection at 8 or $40 \mu \mathrm{g} / \mathrm{kg}$ (Figure $9 \mathrm{~A}$ ). The drop in plasma level of total $A \beta 1-42$ in response to the low dose of hA $\beta 1-42$ is reminiscent of that seen with low doses of hPEPD or mSRC as described before. Plasma levels of total $\mathrm{A} \beta 1-42$ were 62.7-94.1-fold higher in $\mathrm{FXII}^{-/ 2}$ mice and FVII ${ }^{\mathrm{ITA} / \mathrm{TA}}$ mice than in WT mice under the same hA $\beta 1-42$ treatment, while the difference between $\mathrm{FXII}^{-1-}$
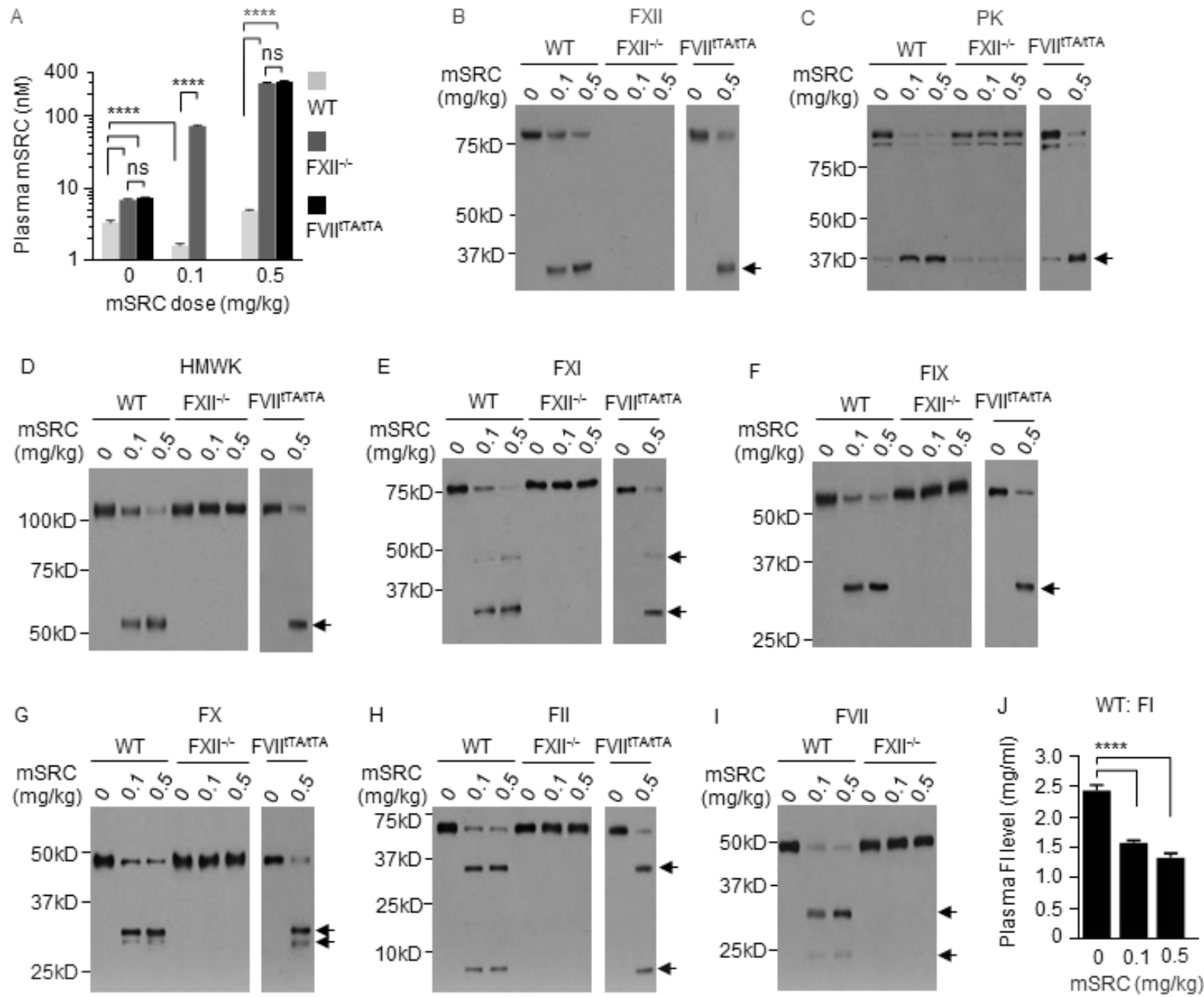

Figure 7: The FXII-FVII proteolysis pathway detects and degrades SRC. WT mice, FXII ${ }^{-/-}$mice and $\mathrm{FVII}^{\mathrm{tTA} / \mathrm{TA}}$ mice were treated with vehicle or mSRC i.p.; blood samples were collected from the mice at $6 \mathrm{~h}$ after treatment. A. Plasma concentrations of mSRC, measured by ELISA. B.-J. Changes in plasma coagulation factors, measured by IB ( $7.5 \mu 1$ plasma per sample) or ELISA. Arrows indicate cleaved fragments. Error bars in A and J indicate SD $(n=3)$. Data were analyzed by two-way ANOVA in A or one-way ANOVA in J, followed by Tukey multiple comparisons test. Data in A were log transformed before ANOVA, **** $p<0.0001$; ns, not significant. 
mice and FVII ${ }^{\mathrm{tTA} / \mathrm{TA}}$ mice was not statistically significant (Figure 9A).

hA $\beta 1-42$ caused the activation/cleavage of FXII, PK, HMWK, FXI, FIX, FX, FII, FI and FVII in WT mice, only slight activation of FX, FII and FVII in $\mathrm{FXII}^{-/-}$mice, and activation of all the above factors, excluding FVII, in FVII ${ }^{\mathrm{TTA} / \mathrm{TAA}}$ mice (Figure 9B-9J). We did not measure FI cleavage in $\mathrm{FXII}^{-/-}$mice and $\mathrm{FVII}^{\mathrm{TA} / \mathrm{tTA}}$ mice. Our results differ from a previous report, which showed that FXII activation by $\mathrm{hA} \beta 1-42$ in WT mice leads to activation/ cleavage of PK and HMWK but no activation of other coagulation factors [36]. The slight FXII-independent activation of FX, FII and FVII by hA $\beta 1-42$ resembles that of hPEPD and mPEPD described before but did not contribute significantly to A $\beta 1-42$ degradation. Although several other proteins were reported to degrade $A \beta 1$ 42 elsewhere $[37,38]$, our results show that $A \beta 1-42$ is degraded exclusively by FVIIa in the plasma via the FXIIFVII pathway.

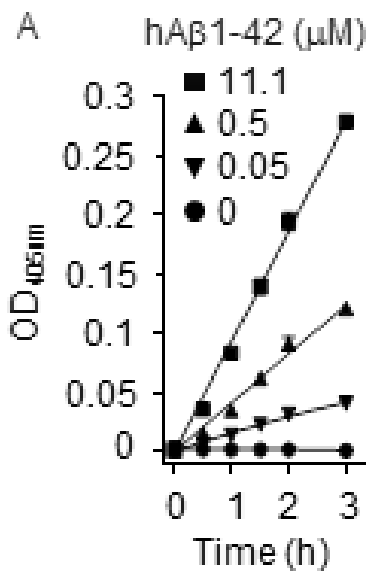

B

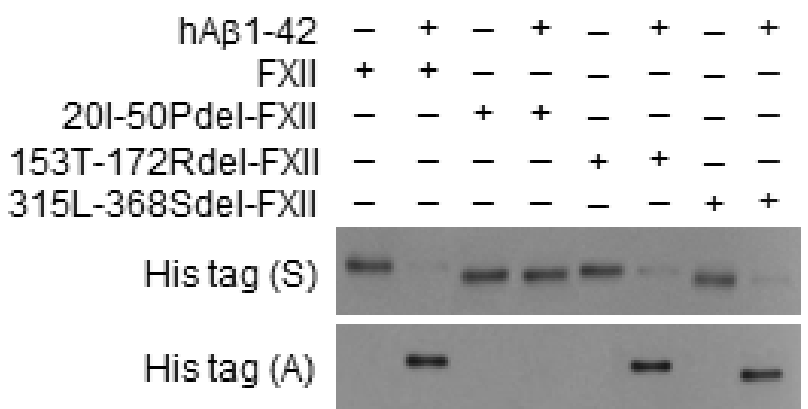

Time (h)
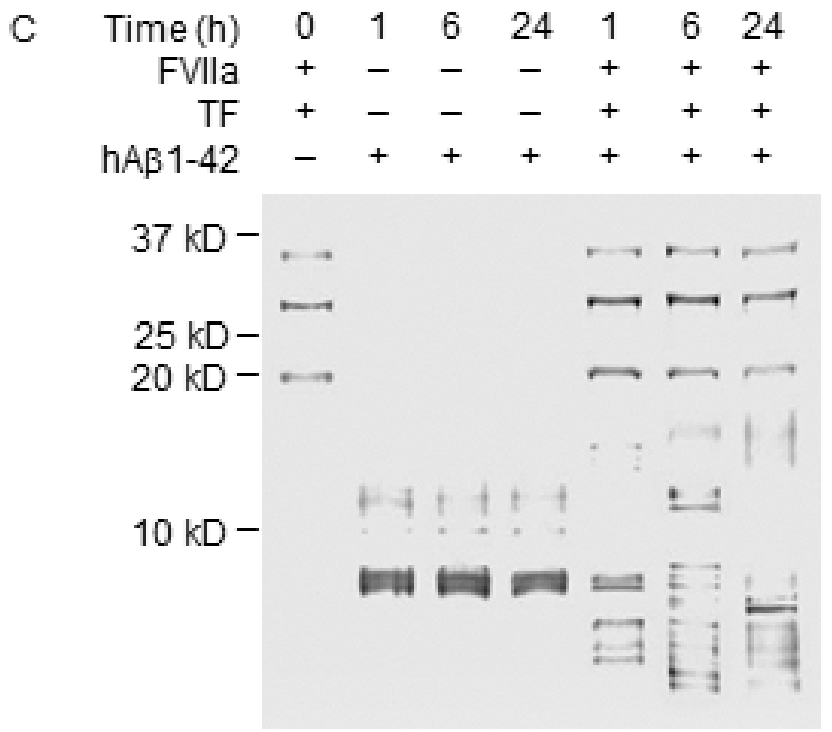

Figure 8: A $\beta 1-42$ binds to FN2D in FXII and activates FXII but is degraded by FVIIa. A. hA $\beta 1-42(0,0.05,0.5$ and 11.1 $\mu \mathrm{M})$ was incubated with FXII $(0.97 \mathrm{nM})$ in $\mathrm{ZnCl}_{2}$-containing PBS at RT; FXII activation was measured by a chromogenic assay. Each value is mean $\pm \mathrm{SD}(n=3)$. B. hA $\beta 1-42(200 \mathrm{nM})$ was incubated with FXII or a mutant $(20 \mathrm{nM})$ in PBS at RT; A $\beta 1-42$ aggregated during the incubation. FXII or its mutant remaining in solution (S) or binding to A $\beta 1-42$ aggregates (A), the latter of which was re-dissolved in $2 \%$ SDS, were measured by IB. C. hAß1-42 $(2.2 \mu \mathrm{M})$ was incubated alone, or with FVIIa $(10 \mathrm{nM})$ and TF $(10 \mathrm{nM})$ in CaCl ${ }_{2}$-containing PBS at RT for indicated times; the aggregates were re-dissolved in $2 \%$ SDS and mixed with the supernatant fraction, separated by SDS-PAGE and stained by silver. FVIIa and TF were incubated without A $\beta 1-42$, as a control. 


\section{EP inhibits the degradation of plasma Aß1-42}

Given that $A \beta 1-42$ is a key driver of $A D$, we sought to determine whether pharmacologically disrupting the FXII-FVII pathway blocks plasma A $\beta 1-42$ degradation. We treated WT mice with vehicle or EP $(2.5 \mathrm{mg} / \mathrm{kg}$ i.p. $)$ once daily for 5 days, and $1 \mathrm{~h}$ after the last EP/vehicle dose, treated the mice i.p. with hA $\beta 1-42(40 \mu \mathrm{g} / \mathrm{kg})$ or vehicle. Blood samples were collected from the mice at $6 \mathrm{~h}$ after $\mathrm{hA} \beta 1-42 /$ vehicle treatment. Average plasma level of endogenous mA $\beta 1-42$ was $0.1 \mathrm{nM}$ in control mice but was 1.7-fold higher in EP-treated mice (Figure 10A). Plasma level of total A $\beta 1-42$ increased 5.5-fold after treatment with hA $\beta 1-42$ alone but increased 406.0fold after treatment with EP plus hA $\beta 1-42$ (Figure 10A). Still, EP did not seem to completely block plasma A $\beta 1-42$ degradation, based on the comparison of the above results with that in $\mathrm{FXII}^{-/}$mice and $\mathrm{FVII}^{\mathrm{TAA} / \mathrm{TA}}$ mice that received the same hA $\beta 1-42$ treatment without EP as described before (Figure 9A).

EP itself had no effect on any of the FXII-FVII pathway factors measured, but greatly inhibited the activation of FX, FII and FVII in hA $\beta 1$-42-treated mice (Figure 10B-10I). These results are similar to that shown in EP inhibition of plasma PEPD degradation as described before.

\section{Activation of the FXII-FVII proteolysis pathway during tissue injury and its protective function}

Carbon tetrachloride $\left(\mathrm{CCl}_{4}\right)$ causes liver damage and increases serum PEPD level, which presumably
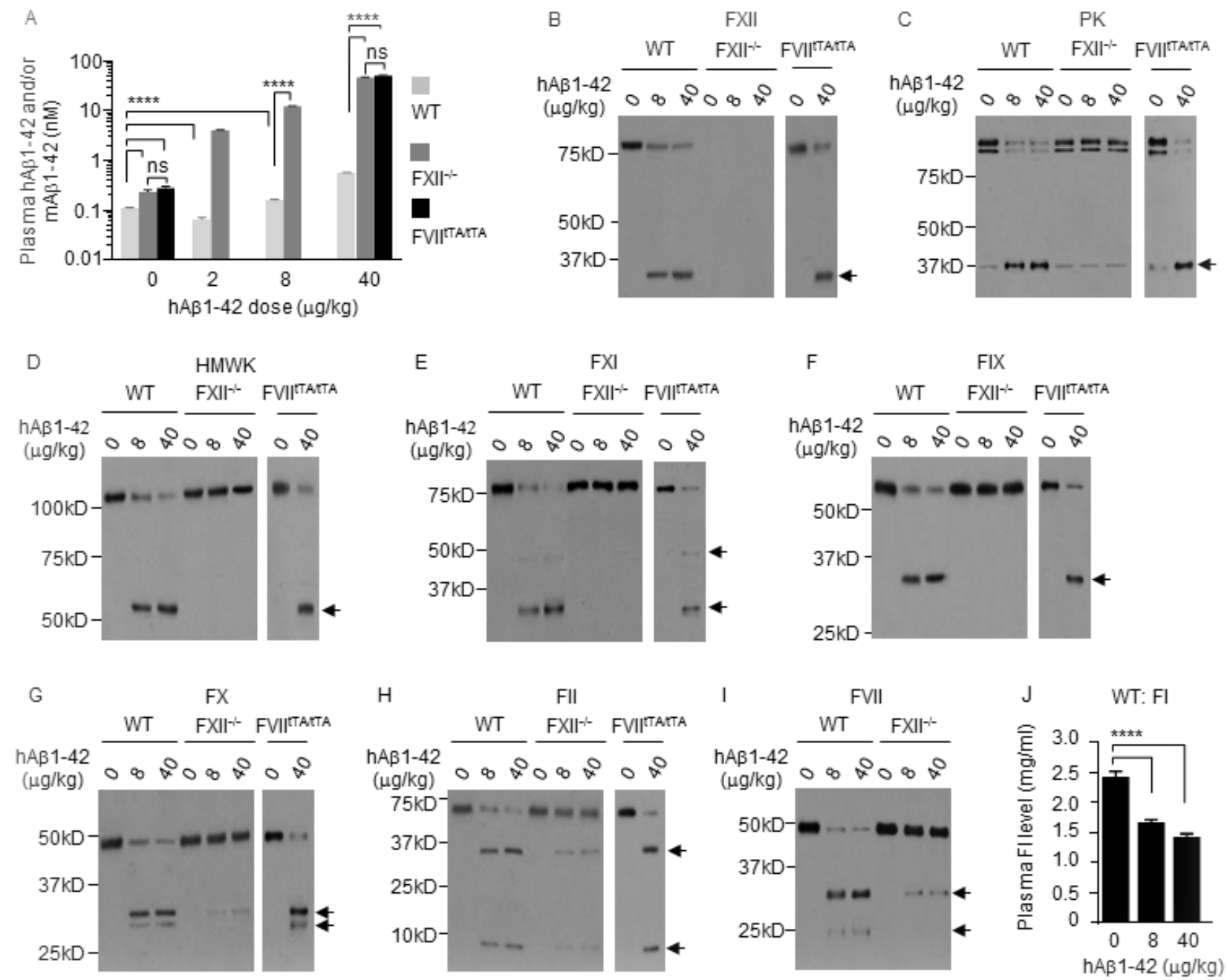

Figure 9: The FXII-FVII proteolysis pathway detects and degrades A $\beta 1-42$. WT mice, $\mathrm{FXII}^{-/-}$mice and $\mathrm{FVII}^{\mathrm{tTA} / \mathrm{TA}}$ mice were treated with vehicle or hA $\beta 1-42$ i.p.; blood samples were collected from the mice at $6 \mathrm{~h}$ after treatment. A. Plasma concentrations of A $\beta 1$ 42, measured by ELISA. B.-J. Changes in plasma coagulation factors, measured by IB (7.5 $\mu 1$ plasma per sample) or ELISA. Arrows indicate cleaved fragments. Error bars in A and J indicate SD $(n=3)$. Data were analyzed by two-way ANOVA in A or one-way ANOVA in J, followed by Tukey multiple comparisons test. Data in A were $\log$ transformed before ANOVA, **** $p<0.0001$; ns, not significant. 
is due to PEPD release from the damaged tissues [11, 39]. $\mathrm{CCl}_{4}$ treatment $(0.5 \mathrm{~g} / \mathrm{kg})$ caused significant but similar liver damage between WT mice and $\mathrm{FXII}^{-/}$mice (Supplementary Figure 7). Plasma level of mPEPD was 2.1-fold higher in $\mathrm{FXII}^{-/}$mice than in WT mice before $\mathrm{CCl}_{4}$ treatment, and at $24 \mathrm{~h}$ after $\mathrm{CCl}_{4}$ treatment, plasma level of mPEPD increased 3.7-fold in WT mice but increased 16.7-fold in $\mathrm{FXII}^{-/}$mice (Figure 11A).
To corroborate the mPEPD results discussed above, we treated mice with hPEPD at $4 \mathrm{mg} / \mathrm{kg}$. This dose of hPEPD was chosen so that plasma level of total PEPD in hPEPDtreated WT mice is similar to that in $\mathrm{CCl}_{4}$-treated WT mice. At $24 \mathrm{~h}$ following hPEPD treatment, plasma level of total PEPD increased 3.3-fold in WT mice but increased 134.6-fold in $\mathrm{FXII}^{-/-}$mice (Figure 11A). Thus, whether PEPD is released from damaged tissues or introduced
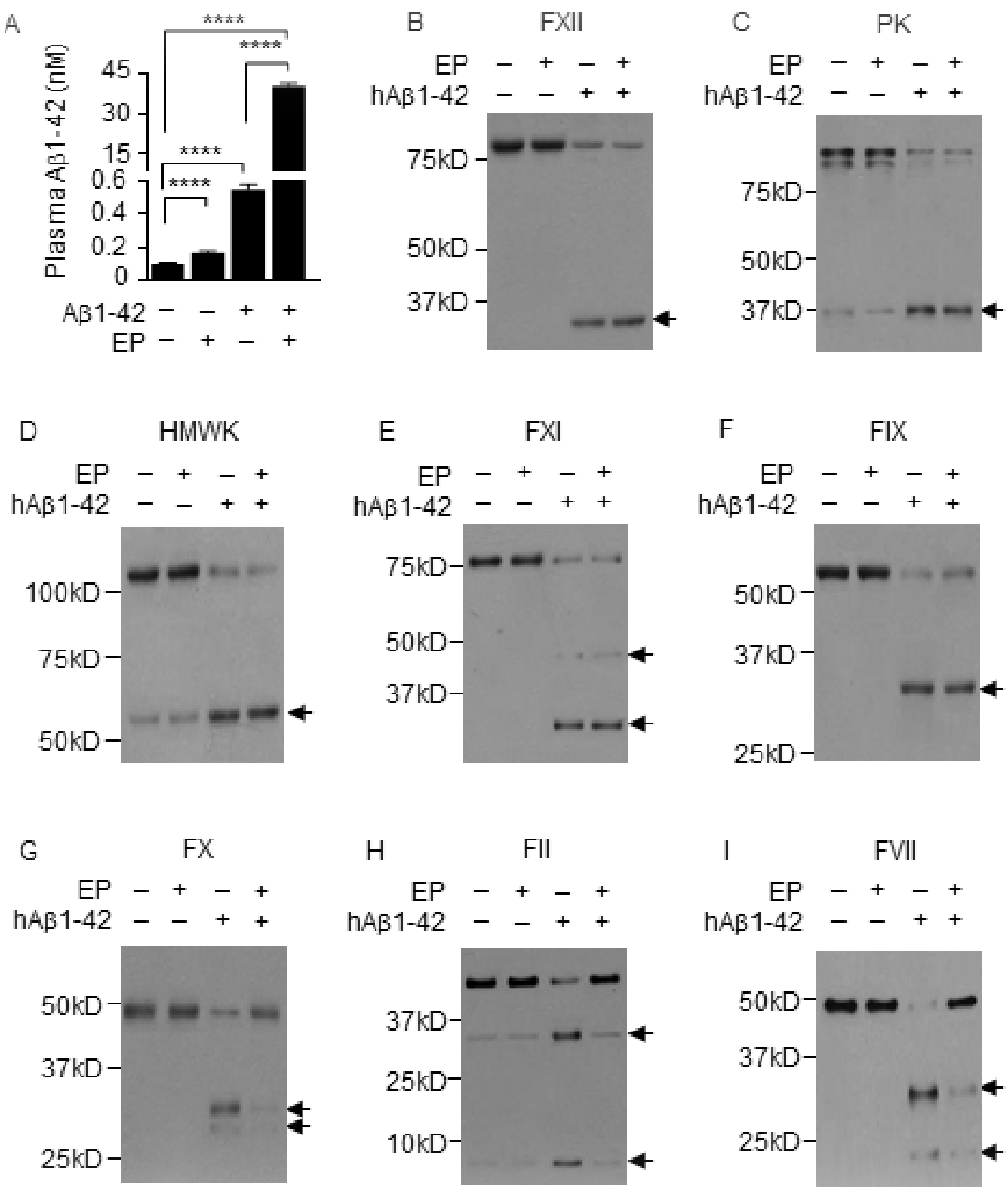

Figure 10: EP inhibits plasma A $\beta 1-42$ degradation and prevents A $\beta 1-42$ from activating FX, FII and FVII. A. Plasma A $\beta 1-42$ concentrations in control mice and mice treated with EP, hA $\beta 1-42$, or EP plus hA $\beta 1-42$. EP (2.5 mg/kg) was given to WT mice i.p. once daily for 5 days. hA $\beta 1-42(40 \mu \mathrm{g} / \mathrm{kg})$ or vehicle was given to mice i.p. alone or $1 \mathrm{~h}$ after the last EP dose. Blood samples were collected from the mice at $6 \mathrm{~h}$ after hA $\beta 1-42 /$ vehicle treatment for measurement of plasma A $\beta 1-42$ by ELISA. Error bars indicate SD $(n=3)$. Data were log transformed before one-way ANOVA, followed by Tukey multiple comparisons test. ${ }^{* * * *} p<0.0001$. B.-I. Changes in plasma coagulation factors in control mice and mice treated with EP, hA $\beta 1-42$, or EP plus hA $\beta 1-42$ as described in A; $7.5 \mu 1$ plasma per sample was analyzed by IB. Arrows indicate cleaved fragments. 
exogenously, it activates the FXII-FVII pathway, which in turn degrades the PEPD. In WT mice treated with $\mathrm{CCl}_{4}$ or hPEPD, average plasma levels of $\mathrm{mSRC}$ and $\mathrm{mA} \beta 1-42$ decreased 41.2-56.1\% (Figure 11B and 11C). In contrast, in $\mathrm{FXII}^{-/}$mice, average plasma levels of $\mathrm{mSRC}$ and $\mathrm{mA} \beta 1-42$ increased $6.7 \%$ and $24.9 \%$, respectively, after $\mathrm{CCl}_{4}$ treatment but remained unchanged after hPEPD treatment (Figure 11B and 11C). The small increase in plasma levels of $\mathrm{mSRC}$ and $\mathrm{mA} \beta 1-42$ in $\mathrm{CCl}_{4}$-treated $\mathrm{FXII}^{-/-}$mice may be due to their release from the damaged tissues. Given that these substances are expressed in a variety of organs and tissues, PEPD in particular [40, 41], the above results suggest that injury in various organs and tissues may activate the FXII-FVII pathway via release of these and other FXII activators to blood circulation. Furthermore, activation of this pathway by one protein may lead to degradation of multiple plasma proteins that are substrates of FVIIa.

PEPD is a ligand of ERBB1 and ERBB2 which are cell surface receptors. We have recently shown that hPEPD binds to ERBB1 and ERBB2 and causes receptor phosphorylation, followed by profound receptor depletion due to its internalization and degradation, resulting in overall inhibition of receptor activity [7, 8, 11]. We sought to determine whether the FXII-FVII pathway may minimize the inhibitory effects of plasma PEPD (released from damaged tissues or entered exogenously) on the receptors. Compared to $\mathrm{FXII}^{-/-}$mice, WT mice treated with $\mathrm{CCl}_{4}$ or hPEPD showed not only lower plasma levels of PEPD (Figure 11A) but also reduced changes in receptor tyrosine phosphorylation (measuring representative phosphorylation sites) and receptor depletion in various tissues (heart, kidney and liver) (Figure 11D). Thus, the FXII-FVII pathway apparently attenuates the inhibitory effect of PEPD on ERBB1 and ERBB2 in normal tissues by degrading plasma PEPD.

\section{DISCUSSION}

The FXII-FVII pathway for detecting and degrading PEPD, SRC and A $\beta 1-42$ as well as its inhibition by EP are summarized in Figure 12. FVIIa degrades PEPD, SRC and A $\beta 1-42$ that are structurally diverse. A previous study also suggests low substrate specificity of FVIIa [21]. PEPD and
A

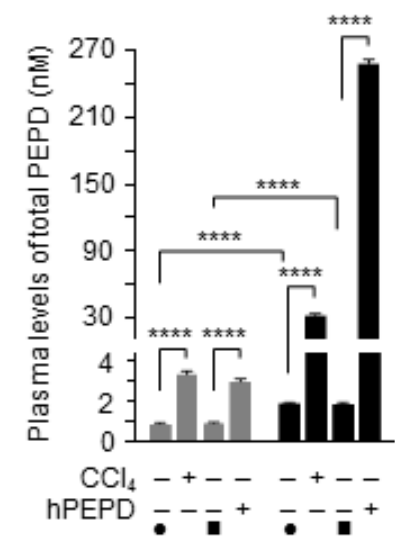

$\mathrm{B}$

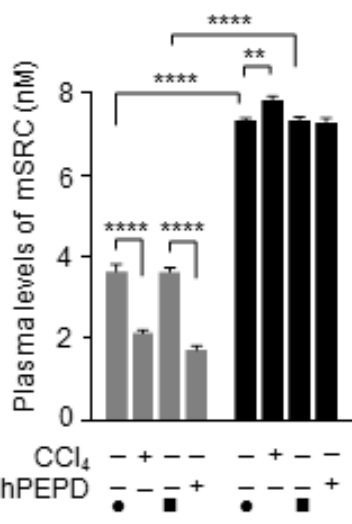

C

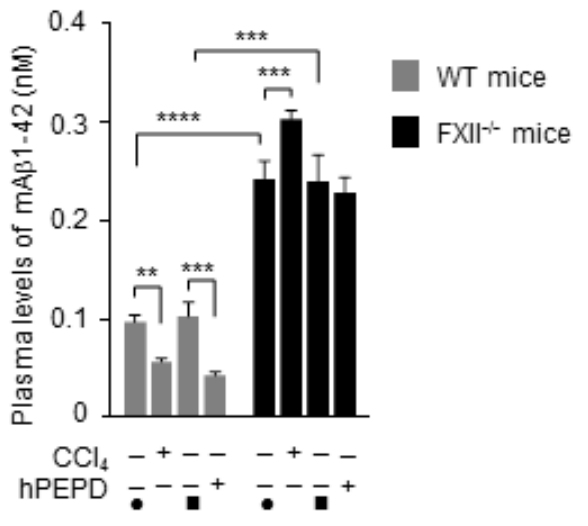

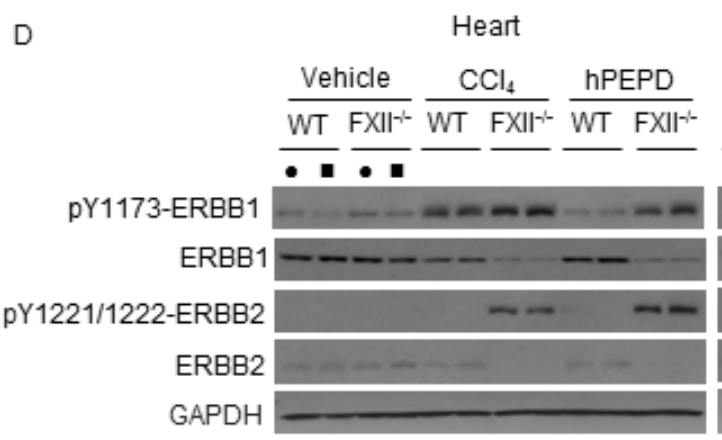

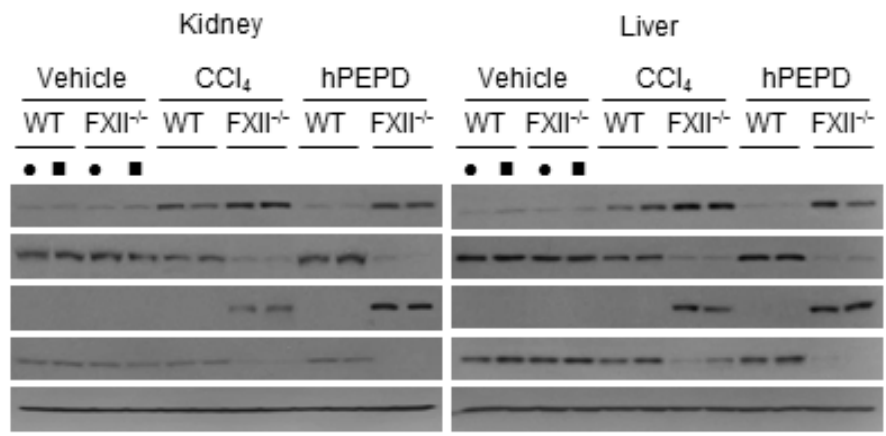

Figure 11: The FXII-FVII proteolysis pathway responds to tissue injury. Mice were treated i.p. with vehicle (filled circle: corn oil for $\mathrm{CCl}_{4}$; filled square: PBS for hPEPD), $\mathrm{CCl}_{4}(0.5 \mathrm{~g} / \mathrm{kg})$ or hPEPD $(4 \mathrm{mg} / \mathrm{kg})$; blood samples and various organs were collected $24 \mathrm{~h}$ later. A.-C. Plasma levels of mPEPD and/or hPEPD, mSRC and mA $\beta 1-42$ were measured by ELISA. Error bars indicate SD $(n=3)$; data were $\log$ transformed before two-way ANOVA, followed by Tukey multiple comparisons test. $* * p<0.01 ; * * * p<0.001 ; * * * * p<0.0001$. D. Tissue levels of ERBB1 and ERBB2 and their phosphorylation status were measured by IB. glyceraldehyde-3-phosphate dehydrogenase $(\mathrm{GAPDH})$ is a loading control. Each lane represents a sample from a different mouse. 
SRC activate FXII by binding to its PRD, whereas A $\beta 1$ 42 activates FXII by binding to its FN2D. Notably, the concentrations of these probes used for FXII activation in vitro are based on their concentrations detected in the plasma of $\mathrm{FXII}^{-/-}$mice and $\mathrm{FVII}^{\mathrm{TTA} / \mathrm{TA}}$ mice following treatment with them; the proteolysis pathway is disrupted in these mice, unlike WT mice in which this pathway was strongly activated under the same treatment conditions, leading to degradation of the probes. Other known activators of FXII interact with FN2D or FN1D in FXII $[36,42,43]$. Thus, multiple domains in FXII mediate its activation. A large number of intracellular proteins bind to proline-rich motifs via their SH3, WW or EVH1 domains [33-35]. Our SRC results suggest that other PRD-binding intracellular proteins may also engage the proteolysis pathway when released into blood circulation. On the other hand, it is possible that other mechanisms may also play a role in clearing these and other proteins and peptides from the circulation, such as renal elimination, hepatic elimination, binding to matrix in various tissues as well as cellular uptake and degradation. Notably, there is only slight activation of various factors of the FXII-FVII pathway in un-treated mice (Supplementary Figure 8), suggesting that this pathway is not significantly activated under normal conditions; detection of such activation was somewhat difficult, as there appeared to be a slight activation of the factors following blood draw before the anticoagulant effect of EDTA kicked in.

Our results indicate that the FXII-FVII pathway may contribute to tissue homeostasis by eliminating unwanted or harmful proteins and peptides from plasma, whereas anticoagulants like EP may elevate plasma level of these substances by disrupting the proteolysis pathway. Notably, no physiological function in the blood is known for PEPD, SRC and $A \beta 1-42$, and $A \beta 1-42$ is even harmful, being a key driver of AD. However, our results also show that activation of this pathway leads to significant cleavage of FI, which may increase blood clot risk, although there was no sign of blood clotting in the mice in the present study. Moreover, activation of this pathway may also lead to bradykinin liberation from HMWK and complement activation via $\beta$-FXIIa and kallikrein, potentially impacting vascular physiology, immune response and inflammation [44-46]. Further study is needed to better understand the protective as well as adverse impact of activation of this pathway.

Our finding that plasma $A \beta 1-42$ is detected and degraded by the FXII-FVII pathway provides insight into AD. Previous studies have shown activation of FXII and certain downstream factors by $\mathrm{A} \beta 1-42$ in $\mathrm{AD}[47,48]$, but our results show that such activation leads to FVII activation and degradation of A $\beta 1-42$ by FVIIa. A $\beta 1-42$ and $A \beta 1-40$ are the main components of senile plaque, one of the hallmarks of AD pathology, and are considered key drivers of $\mathrm{AD}[10,49]$. Like $A \beta 1-42, A \beta 1-40$ is generated from proteolytic cleavage of cell-membrane-bound $\mathrm{A} \beta$ precursor protein by secretases and is also present in the plasma at low levels. A $\beta 1-40$ may also be degraded by the FXII-FVII pathway, as it differs from A $\beta 1-42$ by only two amino acids, and A $\beta 1-40$ also binds to FXII via FN1D [43]. Several other mechanisms of $\mathrm{A} \beta$ clearance have been reported, including $A \beta$ internalization by astrocytes [50], $\mathrm{A} \beta$ degradation by extracellular or intracellular proteases [38], lowering brain $\mathrm{A} \beta$ by peripheral sink such as

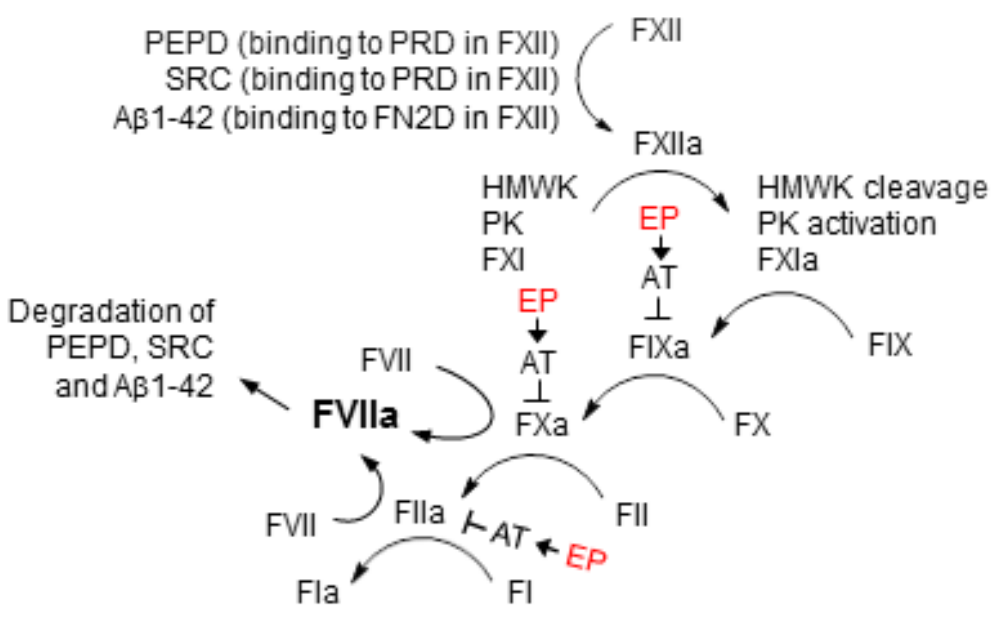

Figure 12: The FXII-FVII proteolysis pathway that detects and degrades PEPD, SRC and Aß1-42, and its inhibition by EP. PEPD, SRC or A $\beta 1-42$ activates FXII by binding to a different domain in FXII. FXII activation leads to activation of FX and FII, which in turn activates FVII, and activated FVII degrades PEPD, SRC and A $\beta 1-42$. EP blocks the degradation of PEPD, SRC and A $\beta 1-42$ in the plasma by binding and activating antithrombin III (AT), which inhibits several coagulation factors in the proteolysis pathway. The " $\downarrow$ " and " $T$ " symbols indicate activation and inhibition, respectively. 
lipoprotein receptors [51], and apolipoprotein E-mediated $\mathrm{A} \beta$ clearance from the brain [52]. However, the fact that total plasma levels of A $\beta 1-42$ are 63-95-fold higher in mice deficient in either FXII or FVII or in EP-pretreated WT mice than in EP-untreated WT mice following hA $\beta 1$ 42 injection (Figure 9A and 10A) is a clear evidence that the newly discovered plasma proteolysis pathway plays a pivotal role in plasma $A \beta 1-42$ clearance.

Moreover, our finding that EP inhibits plasma A $\beta 1-42$ degradation may provide a novel approach for development of $\mathrm{AD}$ biomarkers. Blood-based biomarkers of $\mathrm{AD}$ are an unmet medical need. Plasma $\mathrm{A} \beta$ level correlates poorly with brain plaque burden and is not currently considered an AD biomarker [53-56]. Our results suggest that temporary inhibition of the FXII-FVII proteolysis pathway, e.g., using EP, may enable detection of high plasma levels of $A \beta 1-42$ and other $A \beta$ forms in $\mathrm{AD}$, and that such an approach may enable development of plasma $\mathrm{A} \beta$ as an $\mathrm{AD}$ biomarker for disease detection as well as for assessment of disease progression and response to treatment. Interestingly, there is also evidence that EP is a potential therapeutic agent for AD as well. Chronic treatment of AD transgenic mice (APP23 mice or APPswe/PS1dE9 mice) with EP (approximately 2.5 $\mathrm{mg} / \mathrm{kg}, 2-3$ times per week) for 3-6 months reduces astrocyte activation and slows disease progression [57, 58]; surprisingly, when EP treatment was started at 5-6 months of age, it reduced brain $A \beta$ accumulation in these mice, although it increased brain $A \beta$ accumulation when EP treatment was started at 10-12 months of age. It remains unclear whether EP blockage of $A \beta$ degradation in the plasma may impact brain $\mathrm{A} \beta$ accumulation. Notably, plasma $A \beta$ level was not measured in the studies mentioned above. The therapeutic activity of EP against AD may result in part from its inhibition of the plasma proteolysis pathway, as this pathway may be strongly activated in $\mathrm{AD}$ transgenic mice, which may promote blood clotting. Indeed, a recent study showed increased blood clotting activity in the brain of $\mathrm{AD}$ transgenic mice [59]. Interestingly, EP was also shown to significantly attenuate $\mathrm{A} \beta$ cytotoxicity in cultured neuronal cells.

Finally, the discovery of the FXII-FVII proteolysis pathway may also have important implications for developing certain protein therapeutics. Many therapeutic proteins have short plasma half-life, and current approaches are aimed at slowing their removal via biliary, hepatic or renal elimination [4]. Our findings raise the possibility that some of these proteins may engage the FXII-FVII pathway and that inhibiting this pathway may increase their retention in plasma. As a case in point, EP inhibits PEPD degradation in vivo and allowed hPEPD dose to be reduced by at least 50 fold without decreasing its plasma concentration required for inhibition of ERBB2driven tumors in mice [8]. Moreover, combination of EP with hPEPD may also make hPEPD a safer antitumor agent, as EP may minimize the stimulating effect of
hPEPD on blood coagulation.

\section{MATERIALS AND METHODS}

\section{Materials}

hPEPD and its mutants (6xHis tagged to the carboxy terminus) were generated, purified and characterized as recently reported $[7,11]$. mPEPD was purified from mouse kidney (Supplementary Methods; Supplementary Figure $1 \mathrm{~A}$ and $1 \mathrm{~B}$ ). $\mathrm{hA \beta 1}-42$ (A9810) and $\mathrm{CCl}_{4}$ were purchased from Sigma-Aldrich. mSRC (50311-M20B) and EP were purchased from Sino Biological and SanofiAventis, respectively. The following human coagulation factors were purchased from Haematologic Technologies: FXII (HCXII-0155), FXI (HCXI-0150), FX (HCX0050), FXa (HCXA-0060), FVII (HCVII-0030), FVIIa (HCVIIA-0031), TF (RTF-0300), FII (HCP-0010), FIIa (HCT-0020). Human PK (HPK 1302) and human HMWK (HK 1300) were purchased from Enzyme Research Laboratories. The following antibodies were purchased from Santa Cruz Biotechnology: Anti-6XHis tag (sc803), anti-HMWK (sc-25885), anti-FII (sc-16972), antiSRC (sc-8056), anti-Aß1-42 (sc-374527, sc-9129), and a donkey anti-goat IgG-horseradish peroxidase (HRP) (sc-2020). The following antibodies were purchased from Cell Signaling Technology: Anti-ERBB1 (2232), anti-pY1173-ERBB1 (4407), anti-ERBB2 (2165), antipY1221/1222-ERBB2 (2243), and anti-SRC (2123). The following antibodies were purchased from GeneTex: Anti-FXII (GTX21008), anti-FXI (GTX79765), antiFIX (GTX79802), anti-FX (GTX110300), and anti-FVII (GTX79785). Anti-PEPD (ab86507) and anti-GAPDH (MAB374) were purchased from Abcam and Millipore, respectively. A donkey anti-rabbit IgG-HRP (NA934V) and a sheep anti-mouse IgG-HRP (NA931V) were purchased from GE Healthcare.

\section{Generation of recombinant human FXII and its mutants}

Recombinant human FXII and its mutants with 6XHis C-terminal tag (Supplementary Figure 4A and 4B) were generated as described below. The full length human FXII coding sequence without a stop codon was amplified by PCR from normal human liver cDNA using the primers shown in Supplementary Table 1, which contain unique restriction sites. The PCR conditions were as follows: 95 ${ }^{\circ} \mathrm{C}$ for $3 \mathrm{~min}, 29$ cycles of $94{ }^{\circ} \mathrm{C}$ for 30 seconds, $61^{\circ} \mathrm{C}$ for 30 seconds, and $68{ }^{\circ} \mathrm{C}$ for $2 \mathrm{~min}$, with a final extension at $68{ }^{\circ} \mathrm{C}$ for $10 \mathrm{~min}$. Amplified PCR products were digested with applicable restriction enzymes (EcoR1 and SalI), followed by ligation into pCMV6-XL5 (Origene), which was pre-digested with the same restriction enzymes. $6 \mathrm{XHis}$ 
C-terminal tag was added to the expression construct by PCR-based site-directed mutagenesis using the primers listed in Supplementary Table 1. The insert was confirmed by DNA sequence analysis. Mutation of proline to alanine as well as specific deletion in the FXII coding sequence, including 20I-50Pdel-FXII, 153T-172Rdel-FXII, 315L-368Sdel-FXII, 6Psdel-FXII, and 13Ps $>13$ As-FXII, were accomplished using QuikChange Lightning Multi Site-Directed Mutagenesis Kit or QuikChange Lightning Site-Directed Mutagenesis Kit (Agilent Technologies), using primers listed in Supplementary Table 1. All the reactions were carried out according to the manufacturer's instructions. All constructs were sequenced to ensure correct changes. These plasmids were used to generate the recombinant proteins in $\mathrm{CHO}-\mathrm{K} 1$ cells (ATCC). CHO-K1 cells were cultured in F-12K medium (Gibco) supplemented with 10\% FBS (Gibco) in a humidified incubator at $37{ }^{\circ} \mathrm{C}$ with $5 \% \mathrm{CO}_{2}$. Cells growing in 6-well plates were transfected with the pCMV6-XL5 plasmids expressing FXII or a mutant as described above, using FuGENE HD (Promega), at 1-2 $\mu \mathrm{g}$ of DNA per well for $48 \mathrm{~h}$. Cells were then harvested, washed with PBS and suspended in a lysis buffer $\left(50 \mathrm{mM} \mathrm{NaH} \mathrm{PO}_{4}, 300\right.$ $\mathrm{mM} \mathrm{NaCl}, 10 \mathrm{mM}$ imidazole, $0.05 \%$ Tween 20 , with $\mathrm{pH}$ adjusted to 8.0 using $\mathrm{NaOH}$ ) at $0.5 \mathrm{ml}$ per $10^{7}$ cells. Cell lysis was enhanced by sonication on ice. The lysates were cleared of debris by centrifugation at 10,000 $\mathrm{x}$ g for 10 min at $4{ }^{\circ} \mathrm{C}$. The 6 XHis-tagged FXII and its mutants were purified by Ni-NTA agarose chromatography. The relative molecular size of each protein was checked by IB (Supplementary Figure 4C), and high purity of each protein was confirmed by sodium dodecyl SDS-PAGE and silver staining, using a kit (LC 6070) from Invitrogen (Supplementary Figure 4D). Protein concentrations of all samples were measured by the bicinchoninic acid (BCA) protein assay kit (Pierce).

\section{Animal studies}

All animal studies were performed in accordance with protocols approved by the Institutional Animal Care and Use Committee at Roswell Park Cancer Institute. Male mice at 7-8 weeks of age were used, including wild type (WT) mice (C57BL/6), and mice deficient in FXII $\left(\mathrm{C} 57 \mathrm{BL} / 6-\mathrm{FXII}^{-/ 2}\right)$ or FVII $\left(\mathrm{C} 57 \mathrm{BL} / 6-\mathrm{FVII}^{\mathrm{tTA} / \mathrm{tAA}}\right)$. WT $\mathrm{C} 57 \mathrm{BL} / 6$ mice were purchased from Taconic. C57BL/6$\mathrm{FXII}^{-/}$mice and $\mathrm{C} 57 \mathrm{BL} / 6-\mathrm{FVII}^{\mathrm{tTA} / \mathrm{TA}}$ mice were bred in our own facility and genotyped as previously described $[30,31]$. The breeders were kindly provided by Dr. Francis J. Castellino at University of Notre Dame. All treatments were given by i.p. as follows: A single dose of vehicle, hPEPD, mPEPD, mSRC, hA $\beta 1-42$ or $\mathrm{CCl}_{4}$; EP once daily for 5 days, followed at $1 \mathrm{~h}$ after the last dose of EP with a single dose of vehicle, hPEPD or hA $\beta 1-42$. $\mathrm{CCl}_{4}$ was dissolved in corn oil, whereas all other substances were dissolved in PBS. The vehicle or the test substance was given to mice in $0.1 \mathrm{ml}$ volume per $20 \mathrm{~g}$ body weight. Blood was collected from the mice at specific times by cardiac puncture at the time of sacrifice by carbon dioxide, and heart, liver and kidney were also collected from some of the mice. Blood was collected into K3 EDTAcontaining tubes (Multivette 600 from Sarstedt), unless specified otherwise. All blood samples were promptly centrifuged to obtain plasma samples.

\section{Measurement of plasma levels of PEPD, SRC, A $\beta 1-42$ and FI}

Plasma concentrations of hPEPD, mPEPD, mSRC, hA $\beta 1-42, m A \beta 1-42$ and FI (also known as fibrinogen) were determined by ELISA. ELISA for measuring plasma concentrations of hPEPD and mPEPD was described previously [11]. To measure plasma levels of $\mathrm{mA} \beta 1-42$, total $A \beta 1-42$ (mA $\beta 1-42$ plus hA $\beta 1-42)$ or mSRC, 96-well ELISA plates were coated with an anti-A $\beta 1-42$ mouse monoclonal antibody (sc-374527) or an anti-SRC mouse monoclonal antibody (sc-8056) at $0.25 \mu \mathrm{g} / 100 \mu \mathrm{l} /$ well at $4{ }^{\circ} \mathrm{C}$ overnight. The plates were washed three times with phosphate buffered saline tween-20 (PBST) and the coated wells were blocked by incubation with $200 \mu \mathrm{l} /$ well of $1 \% \mathrm{BSA}$ in PBS for at least $2 \mathrm{~h}$ at RT. After another round of wash with PBST, the plates were incubated with appropriately diluted A $\beta 1-42$ standard, SRC standard or plasma samples $(100 \mu \mathrm{l} /$ well $)$ for $2 \mathrm{~h}$ at RT. The plates were then washed with PBST and incubated with an antiA $\beta 1-42$ rabbit polyclonal antibody (sc-9129) or anti-SRC rabbit monoclonal antibody (2123) at $100 \mu \mathrm{l} /$ well for 2 $\mathrm{h}$ at RT. The plates were washed again with PBST, and each well was incubated with a goat anti-rabbit IgG-HRP conjugate $(100 \mu \mathrm{l})$ for $1 \mathrm{~h}$ at RT. After yet another round of wash with PBST, each well was incubated with 100 $\mu 1$ of HRP substrate 3,3',5,5'-tetramethylbenzedine (Cell Signaling, 7004). Upon adequate color development, $100 \mu \mathrm{l}$ of stop solution (Cell Signaling, 7002) was added to each well, and absorbance at $450 \mathrm{~nm}$ was promptly recorded by a microtiter plate reader. Plasma FI concentration was determined using an assay kit (400-374-130050) from GenWay Biotech, following the manufacturer's instruction.

IB

Tissue samples were mixed with RIPA buffer (25 $\mathrm{mM}$ Tris- $\mathrm{HCl}, \mathrm{pH} 7.6,150 \mathrm{mM} \mathrm{NaCl}, 1 \%$ Nonidet P-40, $1 \%$ sodium deoxycholate, $0.1 \%$ SDS), supplemented with $2 \mathrm{mM}$ phenylmethanesulfonyl fluoride, a proteinase inhibitor mix (Roche Applied Science) and phosphatase inhibitor Cocktail 2 (Sigma-Aldrich). Tissue samples were stroked in a Dounce homogenizer, and the homogenates were cleared by centrifugation at $12,000 \mathrm{x}$ g for $15 \mathrm{~min}$ at $4{ }^{\circ} \mathrm{C}$. Protein concentrations in all samples were measured 
by the BCA assay kit. Plasma samples were used without further processing (20 $\mu \mathrm{l}$ per sample). Each sample was mixed with $4 \mathrm{x}$ loading dye, heated for $5 \mathrm{~min}$ at $95^{\circ} \mathrm{C}$ and then resolved by SDS-PAGE (8-12.5\%). Notably, $7.5 \mu 1$ of original plasma per sample was analyzed. The proteins were transferred to polyvinylidene fluoride membrane, probed with specific antibodies and detected using the ECL Plus Kit (Amersham) or the SuperSignal West Pico Kit (Thermo Scientific).

\section{Measurement of in vitro degradation of hPEPD, mSRC and hAß1-42}

To determine whether a blood coagulation factor degrades hPEPD, hPEPD at $90 \mathrm{nM}$ or lower concentrations $(10$ or $40 \mathrm{nM})$ was incubated with solvent, 100 nM FIIa, 100 nM FXa, 10 nM FVIIa with or without $10 \mathrm{nM} \mathrm{TF}$, or $10 \mathrm{nM}$ FVII with or without $10 \mathrm{nM}$ TF and/or $100 \mathrm{nM}$ FIIa in PBS in a total volume of $100 \mu \mathrm{l}$ containing $5 \mathrm{mM} \mathrm{CaCl}$ for desired times at RT. Notably, TF was solubilized in $10 \mathrm{mM}$ CHAPS, which was diluted by 10 -fold in the final assay. To compare the hPEPD-degrading activities of different plasma samples, 9.2 pmol of hPEPD was incubated with $100 \mu$ of plasma from WT mice or $\mathrm{FVII}^{\mathrm{tTA} / \mathrm{TA} A}$ mice at RT, with or without FIIa or FXa (10 pmol), and to maximize detection of any activity, all incubations lasted for $24 \mathrm{~h}$. Notably, blood was drawn into plastic tubes without an anticoagulant but immediately centrifuged to remove cells and platelets; we refer to such sample as plasma in this paper. Although some clotting activity may take place before and during centrifugation of the blood sample, our experiments indicate that activation of coagulation factors, e.g., FVII, is very limited (see Figure 5A). To measure remaining hPEPD, the incubated samples were cleared of potential fibrin clots by centrifugation and then analyzed by SDS-PAGE and silver staining (using the LC 6070 kit from Invitrogen), IB or measurement of hPEPD enzymatic activity. hPEPD enzymatic activity was measured using glycyl-proline as a substrate as previously described [60]. The precipitates from each incubated sample were washed with PBS twice and then resuspended in $2.5 \% \mathrm{SDS}$ ( $20 \mu \mathrm{l}$ per sample); each solution was mixed with $10 \mu \mathrm{l}$ loading dye and analyzed for hPEPD by IB, using pure hPEPD as a standard and factor XIIIa (FXIIIa) as a binding control, respectively.

To measure degradation of hPEPD in plasma samples with or without removal of FVII and FVIIa, plasma samples from WT mice as described above were either used directly or immunodepleted of FVII and FVIIa before use. To remove FVII and FVIIa from plasma, 500 $\mu l$ plasma was incubated with an antibody specific for FVII/FVIIa (GTX79785; $10 \mu \mathrm{g}$ ) and protein A sepharose beads for $1 \mathrm{~h}$ at RT. Following centrifugation at 13,000 x $\mathrm{g}$ for $1 \mathrm{~min}$ at $4{ }^{\circ} \mathrm{C}$, the supernatant fraction was collected and analyzed by IB to confirm depletion of FVII and FVIIa. Next, 9.2 pmol of hPEPD was incubated with 100 $\mu l$ of regular plasma or the plasma depleted of FVII/FVIIa, with or without FIIa (10 pmol) for $24 \mathrm{~h}$ at RT. Potential fibrin clots formed during the incubation was removed by centrifugation at the end of the incubation, and remaining hPEPD was measured by hPEPD enzymatic activity analysis.

To measure degradation of mSRC or hA $\beta 1-42$ by FVIIa, mSRC $(0.17 \mu \mathrm{M})$ or hA $\beta 1-42(2.2 \mu \mathrm{M})$ was incubated with or without FVIIa $(10 \mathrm{nM})$ and TF (10 $\mathrm{nM})$ in PBS in a total volume of $100 \mu$ containing $5 \mathrm{mM}$ $\mathrm{CaCl}_{2}$ for desired times at RT. All samples after incubation were resolved by SDS-PAGE and stained by silver. In the case of $A \beta 1-42$ which aggregated during the incubation, the aggregates were re-dissolved in $30 \mu \mathrm{l}$ of $2 \%$ SDS and combined with the supernatant fraction before SDSPAGE.

\section{Measurement of binding of hPEPD, mSRC or hAß1-42 to a coagulation factor or its mutant}

Binding reactions were carried out in PBS in a total volume of $100 \mu \mathrm{l}$ for $2 \mathrm{~h}$ at $37^{\circ} \mathrm{C}$. To assess binding of hPEPD to HMWK, PK, FXI, FXII or a FXII mutant, $\mathrm{hPEPD}$ at $40 \mathrm{nM}$ was incubated with a potential binding partner at $0.5 \mu \mathrm{M}$. All FXII mutants are His tagged, while FXII is either 6XHis-tagged (generated in our own laboratory) or not His-tagged (purchased commercially), depending on the experiment. To compare hPEPD and its mutants for binding to FXII, hPEPD or a mutant (40 nM) was incubated with FXII at $0.5 \mu \mathrm{M}$. Likewise, to assess binding of mSRC to FXII and its mutants, mSRC (40 nM) was incubated with FXII or a mutant at $0.5 \mu \mathrm{M}$. At the end of the incubation, $300 \mu \mathrm{l}$ PBS containing a specific primary antibody was added to the incubation solution, which was further incubated at $4{ }^{\circ} \mathrm{C}$ overnight, followed by IP by protein G-agarose, and the precipitates were analyzed by IB. The above approach was not used to assess binding of hA $\beta 1-42$ to FXII and its mutants, due to the tendency of $h A \beta 1-42$ to aggregate. Instead, $h A \beta 1$ 42 (200 nM) was incubated with FXII or a mutant (20 $\mathrm{nM}$ ) in PBS in a total volume of $100 \mu \mathrm{l}$ for $2 \mathrm{~h}$ at RT; the solution was then centrifuged at low speed to separate the supernatants from the precipitates. The precipitates were re-dissolved in $30 \mu \mathrm{l}$ of $2 \% \mathrm{SDS}$, which were analyzed along with the supernatants by IB.

\section{Measurement of FXII activation}

FXII activation by hPEPD, its mutants, mSRC or $\mathrm{hA} \beta 1-42$ in vitro was measured by a chromogenic assay as described previously [36]. hPEPD and its mutants were each evaluated at 40 and $400 \mathrm{nM}$. hA $\beta 1-42$ was evaluated at $0.05,0.5$ and $11.1 \mu \mathrm{M}$. mSRC was evaluated at 20 and 
$200 \mathrm{nM}$. FXII activation was followed for $3 \mathrm{~h}$ at RT by monitoring the conversion of the chromogenic substrate at $405 \mathrm{~nm}$ by a microtiter plate reader. Notably, the assay specifically measures FXII activation, as omission of FXII from the reaction solution abrogated conversion of the chromogenic substrate in all reactions in our experiments.

\section{Statistical analysis}

Data were analyzed by analysis of variance (ANOVA), followed by Tukey multiple comparisons test. For data that are highly skewed, log transformation was performed before ANOVA, as indicated in figure legend. $P$ value of 0.05 or lower was considered statistically significant

\section{ACKNOWLEDGMENTS}

We thank Dr. Francis J Castellino (University of Notre Dame) for providing breeders of $\mathrm{FXII}^{-/-}$mice and FVII $^{\mathrm{tTA} / \mathrm{TA}}$ mice. This work was supported in part by NCI grants R01-CA164574 and P30-CA016056, and a Roswell Park Cancer Institute Bridge Fund.

\section{CONFLICTS OF INTEREST}

There are no conflicts of interest.

\section{Editorial note}

This paper has been accepted based in part on peerreview conducted by another journal and the authors' response and revisions as well as expedited peer-review in Oncotarget.

\section{REFERENCES}

1. Appelqvist $\mathrm{H}$, Waster $\mathrm{P}$, Kagedal $\mathrm{K}$, Ollinger $\mathrm{K}$. The lysosome: from waste bag to potential therapeutic target. J Mol Cell Biol. 2013; 5: 214-226.

2. Glickman MH, Ciechanover A. The ubiquitin-proteasome proteolytic pathway: destruction for the sake of construction. Physiol Rev. 2002; 82: 373-428.

3. Hoyt MA, Coffino P. Ubiquitin-free routes into the proteasome. Cell Mol Life Sci. 2004; 61(13): 1596-1600.

4. Tang L, Persky AM, Hochhaus G, Meibohm B. Pharmacokinetic aspects of biotechnology products. J Pharm Sci. 2004; 93: 2184-2204.

5. Barbosa MD, Celis E. Immunogenicity of protein therapeutics and the interplay between tolerance and antibody responses. Drug Discov Today. 2007; 12: 674681.

6. Lupi A, Tenni R, Rossi A, Cetta G, Forlino A. Human prolidase and prolidase deficiency: an overview on the characterization of the enzyme involved in proline recycling and on the effects of its mutations. Amino Acids. 2008; 35 : 739-752.

7. Yang L, Li Y, Zhang Y. Identification of prolidase as a high affinity ligand of the ErbB2 receptor and its regulation of ErbB2 signaling and cell growth. Cell Death Dis. 2014; 5: e1211.

8. Yang L, Li Y, Bhattacharya A, Zhang Y. Inhibition of ERBB2-overexpressing tumors by recombinant human prolidase and its enzymatically inactive mutant. EBioMedicine. 2015; 2: 396-405.

9. Bjorge JD, Jakymiw A, Fujita DJ. Selected glimpses into the activation and function of Src kinase. Oncogene. 2000; 19: 5620-5635.

10. Huang Y, Mucke L. Alzheimer mechanisms and therapeutic strategies. Cell. 2012; 148: 1204-1222.

11. Yang L, Li Y, Ding Y, Choi KS, Kazim AL, Zhang Y. Prolidase directly binds and activates epidermal growth factor receptor and stimulates downstream signaling. J Biol Chem. 2013; 288: 2365-2375.

12. Caliskan A, Yavuz C, Karahan O, Yazici S, Guclu O, Demirtas S, Mavitas B. Factor-Xa inhibitors protect against systemic oxidant damage induced by peripheral-ischemia reperfusion. J Thromb Thrombolysis. 2014; 37: 464-468.

13. Davie EW, Ratnoff OD. Waterfall sequence for intrinsic blood clotting. Science. 1964; 145: 1310-1312.

14. Davie EW, Fujikawa K, Kisiel W. The coagulation cascade: initiation, maintenance, and regulation. Biochemistry. 1991; 30: 10363-10370.

15. Mauray S, de Raucourt E, Talbot JC, Dachary-Prigent J, Jozefowicz M, Fischer AM. Mechanism of factor IXa inhibition by antithrombin in the presence of unfractionated and low molecular weight heparins and fucoidan. Biochim Biophys Acta. 1998; 1387: 184-194.

16. Hirsh J, Raschke R. Heparin and low-molecular-weight heparin: the Seventh ACCP Conference on Antithrombotic and Thrombolytic Therapy. Chest. 2004; 126: 188S-203S.

17. Radcliffe R, Nemerson Y. Activation and control of factor VII by activated factor $\mathrm{X}$ and thrombin. Isolation and characterization of a single chain form of factor VII. J Biol Chem. 1975; 250: 388-395.

18. Bajaj SP, Rapaport SI, Brown SF. Isolation and characterization of human factor VII. Activation of factor VII by factor Xa. J Biol Chem. 1981; 256: 253-259.

19. Bogdanov VY, Balasubramanian V, Hathcock J, Vele O, Lieb M, Nemerson Y. Alternatively spliced human tissue factor: a circulating, soluble, thrombogenic protein. Nat Med. 2003; 9: 458-462.

20. von Ahsen N, Lewczuk P, Schutz E, Oellerich M, Ehrenreich H. Prothrombin activity and concentration in healthy subjects with and without the prothrombin G20210A mutation. Thromb Res. 2000; 99: 549-556. 
21. Larsen KS, Ostergaard H, Bjelke JR, Olsen OH, Rasmussen HB, Christensen L, Kragelund BB, Stennicke HR. Engineering the substrate and inhibitor specificities of human coagulation Factor VIIa. Biochem J. 2007; 405: 429438.

22. Schmidt AE, Bajaj SP. Structure-function relationships in factor IX and factor IXa. Trends Cardiovasc Med. 2003; 13: $39-45$.

23. Leonardi A, Fox JW, Trampus-Bakija A, Krizaj I. Two coagulation factor $\mathrm{X}$ activators from Vipera a. ammodytes venom with potential to treat patients with dysfunctional factors IXa or VIIa. Toxicon. 2008; 52: 628-637.

24. Griffin JH, Cochrane CG. Mechanisms for the involvement of high molecular weight kininogen in surface-dependent reactions of Hageman factor. Proc Natl Acad Sci USA. 1976; 73: 2554-2558.

25. Maher MJ, Ghosh M, Grunden AM, Menon AL, Adams MW, Freeman HC, Guss JM. Structure of the prolidase from Pyrococcus furiosus. Biochemistry. 2004; 43: 2771 2783.

26. Besio R, Alleva S, Forlino A, Lupi A, Meneghini C, Minicozzi V, Profumo A, Stellato F, Tenni R, Morante $\mathrm{S}$. Identifying the structure of the active sites of human recombinant prolidase. Eur Biophys J. 2010; 39: 935-945.

27. Ledoux P, Scriver CR, Hechtman P. Expression and molecular analysis of mutations in prolidase deficiency. Am J Hum Genet. 1996; 59: 1035-1039.

28. Stavrou E, Schmaier AH. Factor XII: what does it contribute to our understanding of the physiology and pathophysiology of hemostasis \& thrombosis. Thromb Res. 2010; 125: 210215.

29. Bernardo MM, Day DE, Olson ST, Shore JD. Surfaceindependent acceleration of factor XII activation by zinc ions. I. Kinetic characterization of the metal ion rate enhancement. J Biol Chem. 1993; 268: 12468-12476.

30. Iwaki T, Castellino FJ. Plasma levels of bradykinin are suppressed in factor XII-deficient mice. Thromb Haemost. 2006; 95: 1003-1010.

31. Rosen ED, Xu H, Liang Z, Martin JA, Suckow M, Castellino FJ. Generation of genetically-altered mice producing very low levels of coagulation factorVII. Thromb Haemost. 2005; 94: 493-497.

32. Greenberg CS, Dobson JV, Miraglia CC. Regulation of plasma factor XIII binding to fibrin in vitro. Blood. 1985; 66: 1028-1034.

33. Staub O, Rotin D. WW domains. Structure. 1996; 4: 495499.

34. Larson SM, Davidson AR. The identification of conserved interactions within the $\mathrm{SH} 3$ domain by alignment of sequences and structures. Protein Sci. 2000; 9: 2170-2180.

35. Ball LJ, Jarchau T, Oschkinat H, Walter U. EVH1 domains: structure, function and interactions. FEBS Lett. 2002; 513: 45-52.

36. Maas C, Govers-Riemslag JW, Bouma B, Schiks B,
Hazenberg BP, Lokhorst HM, Hammarstrom P, ten Cate $\mathrm{H}$, de Groot PG, Bouma BN, Gebbink MF. Misfolded proteins activate factor XII in humans, leading to kallikrein formation without initiating coagulation. J Clin Invest. 2008; 118: 3208-3218.

37. Farris W, Mansourian S, Chang Y, Lindsley L, Eckman EA, Frosch MP, Eckman CB, Tanzi RE, Selkoe DJ, Guenette $\mathrm{S}$. Insulin-degrading enzyme regulates the levels of insulin, amyloid beta-protein, and the beta-amyloid precursor protein intracellular domain in vivo. Proc Natl Acad Sci USA. 2003; 100: 4162-4167.

38. Saido T, Leissring MA. Proteolytic degradation of amyloid beta-protein. Cold Spring Harb Perspect Med. 2012; 2: a006379.

39. Roomi M, Kalinovsky T, Roomi NW, Ivanov V, Rath $\mathrm{M}$, Niedzwiecki A. A nutrient mixture suppresses carbon tetrachloride-induced acute hepatic toxicity in ICR mice. Hum Exp Toxicol. 2008; 27: 559-566.

40. Butterworth J, Priestman DA. Presence in human cells and tissues of two prolidases and their alteration in prolidase deficiency. J Inherit Metab Dis. 1985; 8: 193-197.

41. Liu G, Nakayama K, Awata S, Tang S, Kitaoka N, Manabe $\mathrm{M}$, Kodama H. Prolidase isoenzymes in the rat: their organ distribution, developmental change and specific inhibitors. Pediatr Res. 2007; 62: 54-59.

42. Renne T, Schmaier AH, Nickel KF, Blomback M, Maas C. In vivo roles of factor XII. Blood. 2012; 120: 4296-4303.

43. Maas C, Schiks B, Strangi RD, Hackeng TM, Bouma BN, Gebbink MF, Bouma B. Identification of fibronectin type I domains as amyloid-binding modules on tissue-type plasminogen activator and three homologs. Amyloid. 2008; 15: 166-180.

44. Cichon S, Martin L, Hennies HC, Muller F, Van Driessche K, Karpushova A, Stevens W, Colombo R, Renne T, Drouet C, Bork K, Nothen MM. Increased activity of coagulation factor XII (Hageman factor) causes hereditary angioedema type III. Am J Hum Genet. 2006; 79: 1098-1104.

45. DiScipio RG. The activation of the alternative pathway $\mathrm{C} 3$ convertase by human plasma kallikrein. Immunology. 1982; 45: 587-595.

46. Ghebrehiwet B, Silverberg M, Kaplan AP. Activation of the classical pathway of complement by Hageman factor fragment. J Exp Med. 1981; 153: 665-676.

47. Bergamaschini L, Parnetti L, Pareyson D, Canziani S, Cugno M, Agostoni A. Activation of the contact system in cerebrospinal fluid of patients with Alzheimer disease. Alzheimer Dis Assoc Disord. 1998; 12: 102-108.

48. Zamolodchikov D, Chen ZL, Conti BA, Renne T, Strickland $\mathrm{S}$. Activation of the factor XII-driven contact system in Alzheimer's disease patient and mouse model plasma. Proc Natl Acad Sci USA. 2015; 112: 4068-4073.

49. Andreasson U, Portelius E, Andersson ME, Blennow K, Zetterberg H. Aspects of beta-amyloid as a biomarker for Alzheimer's disease. Biomark Med. 2007; 1: 59-78. 
50. Nielsen HM, Veerhuis R, Holmqvist B, Janciauskiene $\mathrm{S}$. Binding and uptake of A beta1-42 by primary human astrocytes in vitro. Glia. 2009; 57: 978-988.

51. Sagare A, Deane R, Bell RD, Johnson B, Hamm K, Pendu R, Marky A, Lenting PJ, Wu Z, Zarcone T, Goate A, Mayo K, Perlmutter D, et al. Clearance of amyloid-beta by circulating lipoprotein receptors. Nat Med. 2007; 13: 1029 1031.

52. Castellano JM, Kim J, Stewart FR, Jiang H, DeMattos RB, Patterson BW, Fagan AM, Morris JC, Mawuenyega KG, Cruchaga C, Goate AM, Bales KR, Paul SM, et al. Human apoE isoforms differentially regulate brain amyloid-beta peptide clearance. Sci Transl Med. 2011; 3: 89ra57.

53. Blennow $\mathrm{K}$, Hampel $\mathrm{H}$, Weiner $\mathrm{M}$, Zetterberg $\mathrm{H}$. Cerebrospinal fluid and plasma biomarkers in Alzheimer disease. Nat Rev Neurol. 2010; 6: 131-144.

54. Hansson O, Stomrud E, Vanmechelen E, Ostling S, Gustafson DR, Zetterberg H, Blennow K, Skoog I. Evaluation of plasma Abeta as predictor of Alzheimer's disease in older individuals without dementia: a populationbased study. J Alzheimers Dis. 2012; 28: 231-238.

55. Rissman RA, Trojanowski JQ, Shaw LM, Aisen PS. Longitudinal plasma amyloid beta as a biomarker of Alzheimer's disease. J Neural Transm. 2012; 119: 843-850.

56. Toledo JB, Shaw LM, Trojanowski JQ. Plasma amyloid beta measurements - a desired but elusive Alzheimer's disease biomarker. Alzheimers Res Ther. 2013; 5: 8 .
57. Bergamaschini L, Rossi E, Storini C, Pizzimenti S, Distaso M, Perego C, De Luigi A, Vergani C, De Simoni MG. Peripheral treatment with enoxaparin, a low molecular weight heparin, reduces plaques and beta-amyloid accumulation in a mouse model of Alzheimer's disease. J Neurosci. 2004; 24: 4181-4186.

58. Timmer NM, van Dijk L, van der Zee CE, Kiliaan A, de Waal RM, Verbeek MM. Enoxaparin treatment administered at both early and late stages of amyloid beta deposition improves cognition of APPswe/PS1dE9 mice with differential effects on brain Abeta levels. Neurobiol Dis. 2010; 40: 340-347.

59. Cortes-Canteli M, Paul J, Norris EH, Bronstein R, Ahn HJ, Zamolodchikov D, Bhuvanendran S, Fenz KM, Strickland S. Fibrinogen and beta-amyloid association alters thrombosis and fibrinolysis: a possible contributing factor to Alzheimer's disease. Neuron. 2010; 66: 695-709.

60. Zbucka M, Miltyk W, Bielawski T, Surazynski A, Palka J, Wolczynski S. Mechanism of collagen biosynthesis upregulation in cultured leiomyoma cells. Folia Histochem Cytobiol. 2007; 45 Suppl 1: S181-185. 